\title{
CARACTERIZAÇÃO DE BACTÉRIAS DO COMPLEXO Aeromonas ISOLADAS DE PEIXES DE ÁGUA DOCE E SUA ATIVIDADE PATOGÊNICA
}

\author{
ANDRÉA BELÉM COSTA
}

Tese apresentada à Escola Superior de Agricultura

"Luiz de Queiroz", Universidade de São Paulo, para obtenção do título de Doutor em Agronomia, Área de Concentração: Ciência Animal e Pastagens.

P I R A C I C A B A

Estado de São Paulo - Brasil

Março - 2003 


\title{
CARACTERIZAÇÃO DE BACTÉRIAS DO COMPLEXO Aeromonas ISOLADAS DE PEIXES DE ÁGUA DOCE E SUA ATIVIDADE PATOGÊNICA
}

\author{
ANDRÉA BELÉM COSTA \\ Oceanóloga \\ Orientador: Prof. Dr. José EuRICo Possebon CYRINO
}

\begin{abstract}
Tese apresentada à Escola Superior de Agricultura "Luiz de Queiroz", Universidade de São Paulo, para obtenção do título de Doutor em Agronomia, Áreade Concentração: Ciência Animal e Pastagens.
\end{abstract}

P I R A C I C A B A

Estado de São Paulo - Brasil

Março - 2003 
Dados Internacionais de Catalogação na Publicação (CIP) DIVISÃO DE BIBLIOTECA E DOCUMENTAÇÃO - ESALQ/USP

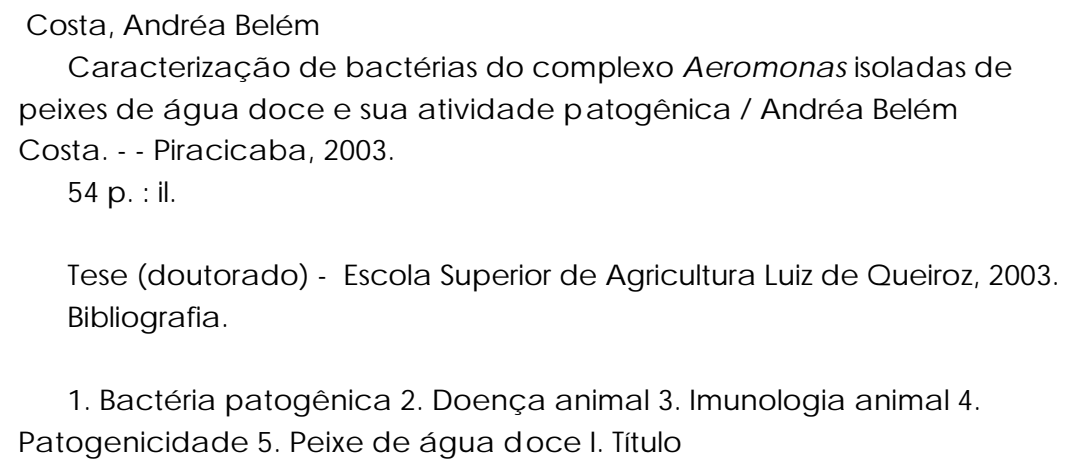

1. Bactéria patogênica 2. Doença a nimal3. Imunologia a nimal 4. Patogenicidade 5. Peixe de água doce I. Título

CDD 639.31 
Aos meus pais Luiz Aurélio e Telma (in memorian)

pelo apoio e amor em todos

momentos da minha vida

DEDICO 
O cientista não estuda a natureza porque ela é útil; estuda-a porque se delicia com ela, e se delicia com ela porque ela é bela. Se a natureza não fosse bela, não valeria a pena conhecê-la e, se não valesse a pena conhecê-la, não valeria a pena viver.

Henri Poincaré 


\section{AGRADECIMENTOS}

A Deus, que criou a Natureza, e que está sempre comigo; A Maria, Mãe de Jesus, que me protege e mostra sempre o melhor caminho a seguir; A Jesus, o Grande Mestre;

A meu pai, o Prof. Luiz Aurélio Castro Costa, por seu exemplo de vida, educação e estímulo constantes;

Ao Prof. Dr. José Eurico Possebon Cyrino, pelo convite para desenvolver este trabalho, pela sua orientação, ensinamentos, confiança e amizade;

À Fundação de Amparo à Pesquisa do Estado de São Paulo, pela concessão da bolsa de estudos e do auxílio pesquisa para a montagem do laboratório para o desenvolvimento deste trabalho;

Ao Departamento de Produção Animal da Escola Superior de Agricultura "Luiz de Queiroz" da Universidade de São Paulo, pela oportunidade de realizar este curso;

Aos técnicos do Setor de Piscicultura do Departamento de Produção Animal da ESALQ, Sérgio Vanderlei Pena e Ismael Baldessin Júnior, pelo apoio na condução dos trabalhos e amizade, e aos funcionários do Departamento de Produção Animal, Vera Lúcia Graciano, Cláudia Chuahy de Camargo e José Henrique Rocha, José Augusto Alves, Otávio Birollo de Lara e Antônio Florêncio da Silva, pela atenção e disponibilidade;

À estagiária do Setor de Piscicultura Jussiara Aparecida Vendemiatti, aos demais colegas da pós-graduação, Daniela Ferraz Bacconi, Ana Cristina Belarmino de Oliveira, Luciane Conte, Ana Maria B.M. Sampaio de Oliveira e Leandro Portz, pela 
amizade e apoio prestados durante o período em que tivemos a oportunidade de convivermos e trabalharmos juntos, como um "cardume de peixes".

À Eliana Acciardo, pelo seu apoio;

Agradeço aos meus irmãos, Samara Belém Costa, Aurélia Belém Costa e Luiz Francisco Belém Costa e Marly Barros Costa, e amigos que me incentivaram nos momentos mais difíceis e que perto ou longe, sempre me apoiaram e me ajudaram a seguir em frente;

Enfim, a todos aqueles que de um modo ou de outro, contribuíram para que este trabalho fosse concluído com sucesso, de coração, fica aqui registrado o meu mais sincero agradecimento. 


\section{SUMÁRIO}

\begin{tabular}{|c|c|}
\hline & Página \\
\hline LISTA DE FIGURAS & ix \\
\hline LISTA DE TABELAS . & $\mathrm{x}$ \\
\hline RESUMO.................................... & $\mathrm{xi}$ \\
\hline SUMMARY & xiii \\
\hline 1 INTRODUÇÃO... & 1 \\
\hline 2 REVISÃO DE LITERATURA ... & 3 \\
\hline 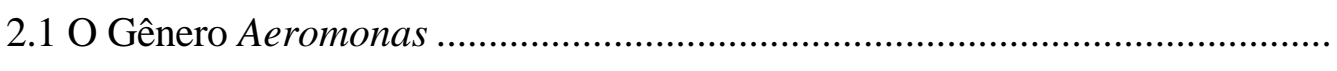 & 3 \\
\hline 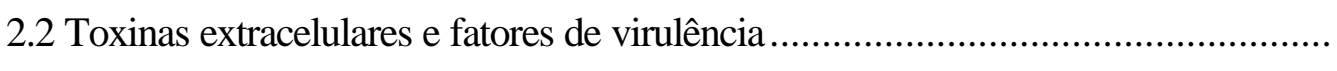 & 4 \\
\hline 2.3 Sinais clínicos associados às Aeromonas móveis ............................................... & 7 \\
\hline $2.4 \mathrm{O}$ controle das infecções causadas por Aeromonas móveis................................. & 8 \\
\hline 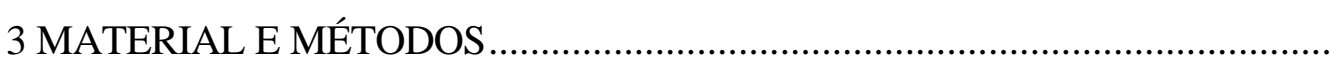 & 12 \\
\hline 3.1 Origem dos organismos ......................... & 12 \\
\hline 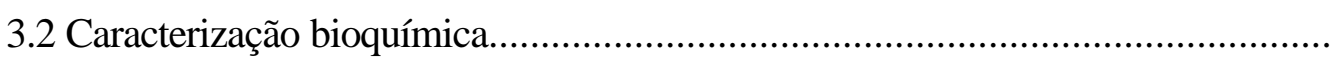 & 13 \\
\hline 3.3 Antibióticos.............................. & 14 \\
\hline 3.4 Análise de proteínas totais ............. & 14 \\
\hline 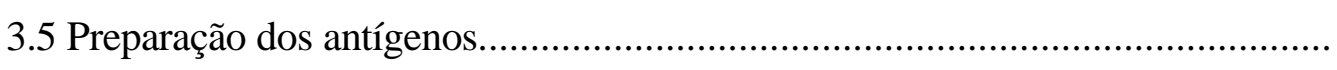 & 15 \\
\hline 3.6 Preparação dos anti-soros.. & 15 \\
\hline
\end{tabular}


3.7 Ensaio sorológico - Aglutinação............................................................. 16

3.8 Extração de antígenos celulares ................................................................. 17

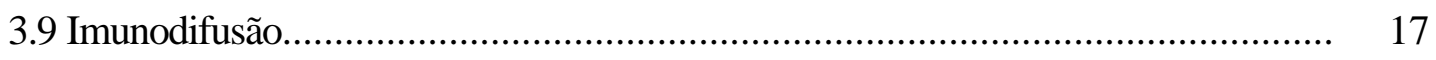

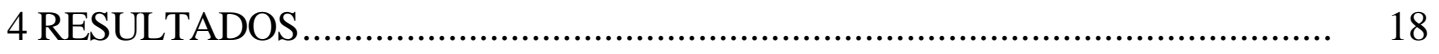

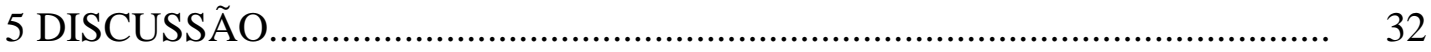

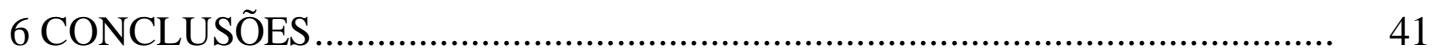

REFERÊNCIAS BIBLIOGRÁFICAS ...................................................... 43 


\section{LISTA DE FIGURAS}

Página

1 Sensibilidade a antibióticos demonstrada pelas linhagens a) LQUSP03, b) LQUSP15, c) LQUSP22 e d)ATCC7966,

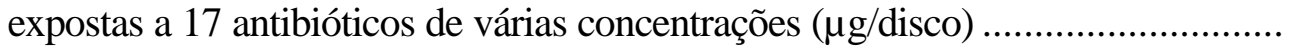

2 Reação sorológica entre os anti-soros produzidos em coelhos e os antígenos bacterianos extraídos a $60^{\circ} \mathrm{C}$

3 Reação sorológica entre os anti-soros produzidos em coelhos e os antígenos bacterianos extraídos a $100^{\circ} \mathrm{C}$

4 SDS-PAGE das linhagens bacterianas cultivadas em dois meios de cultura diferentes 


\section{LISTA DE TABELAS}

Página

1 Isolamentos bacterianos realizados durante epizootias e usados

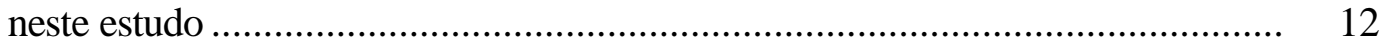

2 Características bioquímicas dos organismos estudados.................................. 20

3 Perfil de sensibilidade das linhagens bacterianas estudadas............................... 23

4 Títulos de aglutinação de anti-soros de A. hydrophila para células mortas por formalina (formalin-killed cells) ......................................... 25

5 Títulos de aglutinação de anti-soros para A. hydrophila para células mortas por calor (heat-killed cells) .................................................. 26

6 Diferenciação entre espécies de Aeromonas e Plesiomonas, modificado de Lee e Donovan (1988)................................................................ 33

7 Algumas características bioquímicas das linhagens estudadas comparadas com características relatadas na literatura..................................... 34 


\title{
CARACTERIZAÇÃO DE BACTÉRIAS DO COMPLEXO Aeromonas ISOLADAS DE PEIXES DE ÁGUA DOCE E SUA ATIVIDADE PATOGÊNICA
}

\author{
Autora: ANDRÉA BELÉM CosTA
}

Orientador: Prof. Dr. JOSÉ EURICO POSSEBON CYRINO

\section{RESUMO}

Pela utilização de métodos bioquímicos, biofísicos, de tipagem sorológica e de visualização das proteínas totais bacterianas, isolados de surubim Pseudoplatystoma corruscans, tilápia Oreochromis niloticus e pacu Piaractus mesopotamicus, foram caracterizados, identificados e sua virulência determinada. Dentre as linhagens de referência, o isolado de surubim caracterizou-se como sendo Plesiomonas shiguelloides e os demais isolados de tilápia e pacu foram identificados como Aeromonas hydrophila, todos pertencentes à família Vibrionaceae. Os isolados de tilápia e pacu caracterizaramse como linhagens virulentas, resistentes aos antibióticos ampicilina, amoxicilina, lincomicina, novobiocina, oxacilina, penicilina, rifampicina e trimetoprim+sulfametoxazol, em ensaios de antibiograma realizados em meio YEA que evidenciaram que as linhagens isoladas de peixes são resistentes a oito das dezessete substâncias antimicrobianas testadas pelo método de difusão em disco. Essas características são compatíveis com as apresentadas pelo espécime tipo de $A$. hydrophila. Ambas as linhagens quando cultivadas em meio YEA compartilharam a mesma banda de aproximadamente $33,61 \mathrm{kDa}$ com o espécime tipo para A. hydrophila. Em meio enriquecido com glucose, a banda compartilhada entre elas teve peso molecular aproximado de $144,28 \mathrm{kDa}$. Os testes de aglutinação sorológica evidenciaram nestas duas linhagens a presença de antígenos estáveis ao calor do tipo O. A técnica de 
dupla imunodifusão de Ouchterlony demonstrou que o antígeno preparado a partir do isolado de tilápia é a linhagem de A. hydrophila mais indicada para ser utilizada em estudos visando o desenvolvimento de uma vacina polivalente. 


\title{
CHARACTERIZATION AND PATHOLOGICAL ACTIVITIES OF Aeromonas BACTERIAL COMPLEX ISOLATED FROM FRESHWATER FISH
}

\author{
Author: ANDRÉA BELÉM COSTA \\ Adviser: Prof. Dr. JosÉ EURICO POSSEBON CYRINO
}

\section{SUMMARY}

Bacteria isolated from surubim Pseudoplatystoma corruscans, tilapia Oreochromis niloticus e pacu Piaractus mesopotamicus, were characterized and identified by biochemical, biophysical, serology, and SDS-PAGE, and their virulence observed. The strain isolated from surubim was characterized as Plesiomonas shigelloides. The other strains isolated from tilapia and pacu were Aeromonas hydrophila. The isolated A. hydrophila strains presented virulence and resistance against the follow antibacterial substances: ampicillin, amoxicillin, lincomicin, novobiocin, oxacillin, penicillin, rifampin and trimetoprim+sulfametoxazole. Both strains when cultivated in YEA medium shared with the A. hydrophila type strain a similar protein band of $33,61 \mathrm{kDa}$. In a medium supplemented with glucose, only one protein exhibiting relative molecular mass of $144.28 \mathrm{kDa}$, was shared by the type strains isolated from fish and the type strain. The serology tests revealed that all isolated strains presented heatstable O-antigens. The Ouchterlony double-immunodiffusion showed that the antigen prepared from the tilapia strain possessed surface antigens similar to A. hydrophila type strain and the strains isolated from pacu. This suggested the possibility of development and usage of a common or polyvalent vaccine for A. hydrophila among tilapia and pacu or other freshwater fish species. 


\section{INTRODUÇÃO}

Com o crescimento da piscicultura intensiva no país observa-se o aumento na ocorrência de doenças nos sistemas de produção de peixes. Muitos dos agentes etiológicos envolvidos em tais problemas ainda não foram identificados e os processos mórbidos que causam foram pouco estudados. Dentre estes agentes destacam-se as bactérias do gênero Aeromonas. Embora vários casos suspeitos de contaminação de pisciculturas brasileiras por bactérias deste gênero tenham sido registrados, a ocorrência e as enfermidades causadas por estas bactérias ainda não foram devidamente caracterizadas.

As bactérias do gênero Aeromonas são um dos principais agentes com potencial patogênico que causam perdas consideráveis em piscicultura. São bactérias Gram-negativas, anaeróbicas facultativas, não esporulantes, móveis, com um flagelo polar e resistente ao agente Vibriostat O/129 (Roberts, 1993). Estão presentes naturalmente ecossistema aquático de criação e fazem parte da flora microbiana normal de organismos aquáticos. Estes microorganismos podem causar enfermidades em animais pecilotérmicos e homeotérmicos, incluindo o homem (Salton \& Schnick, 1973; Fraire, 1978) e estão associadas à hemorragia septicêmica em peixes de água doce.

As espécies de bactérias classificadas como gênero Aeromonas e que causam problemas em peixes de água doce são: Aeromonas hydrophila, A. sobria e A. caviae. Aeromonas salmonicida é a única espécie do complexo Aeromonas não-móvel e que é um patógeno obrigatório de peixes (Griffin et al., 1953). No entanto, é provável que sob a designação de $A$. hydrophila existam, na realidade, várias espécies, principalmente no Brasil, uma vez que possuímos uma grande variedade de ambientes aquáticos naturais e 
uma enorme quantidade de espécies de peixes, gerando assim uma alta biodiversidade no complexo Aeromonas.

O aumento da atividade aquícola nos corpos de água doce traz, como consequiência, o risco de epidemias causadas por bactérias patogênicas, o que tende a ser cada vez maior, já que modifica-se o ambiente natural para a realização de produções semi-intensivas e intensivas de organismos aquáticos. A manutenção de altas densidades de populações de peixes em áreas limitadas, favorece o surgimento e a propagação de doenças responsáveis por grandes mortandades e perdas econômicas significativas.

As doenças de peixes são importante fator limitante no desenvolvimento de sistemas de aqüicultura e as bactérias, dentre os vários patógenos, provavelmente constituam o grupo de agentes etiológicos economicamente mais significante (Frerichs \& Millar, 1993), na moderna aqüicultura mundial. Isto ocorre porque todos os tipos e espécies de peixes são suscetíveis a infecções bacterianas, e não é possível evitar sua propagação, uma vez que estes microorganismos ocorrem naturalmente no ambiente aquático (Costa, 1998a).

A correta caracterização e identificação dos problemas de enfermidades e seus agentes causais é necessária para que se possa conhecê-los adequadamente em relação a seu comportamento, estabelecer a epidemiologia e lançar mão de métodos de control e profilaxia. Com base em tais conhecimentos será possível o desenvolvimento de vacinas, imunoestimulantes e quimioterápicos, evitando-se quebra na produção de pescado e grandes perdas econômicas, ampliando e consolidando a atividade aquícola, além de permitir a identificação e seleção de espécies mais resistentes a doenças.

Os objetivos deste trabalho foram: (1) investigar linhagens de bactérias pertencentes ao complexo Aeromonas móveis, isoladas de diferentes espécies de peixes, a partir da utilização de métodos bioquímicos, biofísicos e sorológicos, e (2) determinar sua patogenicidade e variação sorológica, a fim de lançar bases para o desenvolvimento futuros de vacinas e drogas a serem utilizadas na prevenção e control de enfermidades causadas pela bactéria $A$. hydrophila. 


\section{REVISÃO DE LITERATURA}

\subsection{O Gênero Aeromonas}

As Aeromonas móveis são muito heterogêneas e de taxonomia confusa. Kluyver e van Niel (1936) unificaram vários isolamentos de bactérias e deram origem ao gênero Aeromonas, mais tarde caracterizado como Aeromonas hydrophila, Aeromonas punctata e Aeromonas liquefaciens (Sniezsko, 1957). Esta descrição era baseada principalmente na patogenicidade e em alguns testes bioquímicos e, apesar da legitimação do gênero não ser questionada, ainda permanece certa confusão com relação à especiação, como relatado por Ewing \& Johnstone (1960), Page (1962), Schubert (1967, 1969, 1974).

Schubert (1974) descreveu cinco sub-espécies de Aeromonas móveis, sendo três delas sub-espécies de A. hydrophila e duas sub-espécies de A. punctata. Por sua vez, Popoff \& Veron (1976), publicaram uma complexa análise sobre as Aeromonas móveis onde sugerem a diferenciação em três espécies, A. hydrophila, A. caviae e A. sobria. A maioria das cepas bacterianas patogênicas estão inclusas dentro do primeiro grupo. Esta definição de três espécies foi confirmada pela análise de oligossacarídeos (Shaw \& Hodder, 1978) e por hibridização de DNA (Popoff et al., 1981), mas reconhece-se que dentro destas espécies existem sub-grupos.

Estudos realizados por Austin \& Austin (1987), afirmam que várias espécies distintas podem estar mascaradas dentro do epíteto A. hydrophila e devem ser melhor estudadas. Estas espécies são caracterizadas por motilidade ativa, resultante da presença de um flagelo polar e produção de gás e ácido a partir de carboidratos. São bastonetes ou 


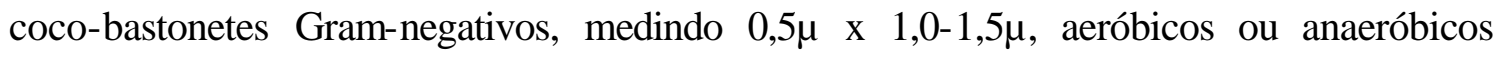
facultativos. São bactérias citocromo oxidase positivas, reduzem nitrato e apresentam mol \% G + C de 57-63\% (Newman, 1982). Geralmente, a diferenciação das espécies é feita com base na utilização de carboidratos e outras reações bioquímicas com as três espécies sendo prontamente separadas com base nos fatores de diferenciação sugeridos por Popoff \& Veron (1976). Com realação a sua estrutura antigênica, as Aeromonas móveis são muito diversas, envolvendo tanto antígenos $\mathrm{H}$ quanto antígenos do tipo $\mathrm{O}$ (Ewing et al., 1961; Takahashi \& Kusuda, 1977).

Segundo Holliman (1993) as Aeromonas móveis são onipresentes no ambiente aquático e um habitante normal do intestino de peixes. Portanto, as septicemias causadas por Aeromonas móveis são um problema comum em todo o mundo, em todas as espécies de peixes de água doce. Deve-se enfatizar ainda que a importância das Aeromonas móveis como patógenos de peixes ainda não foi claramente definida e elas demonstram ampla variação com relação à virulência dentre os diferentes isolados. As Aeromonas móveis mais virulentas pertencem à espécie A. hydrophila.

\subsection{Toxinas extracelulares e fatores de virulência}

Nord et al. (1975) demonstraram que linhagens de A. hydrophila produzem gelatinase, caseinase, elastase, lipase, lecitinase e deoxiribonuclease, juntamente com hemolisinas, citotoxinas e enterotoxinas. As hemolisinas são proteínas citolíticas extracelulares que agem formando furos na membrana celular por sua inserção na camada bi-lipídica, destruindo a barreira de permeabilidade da membrana (Howard \& Buckley, 1985) e dissolvendo as células vermelhas do sangue (Burrows, 1973). As enterotoxinas são produtos extracelulares, excretados para fora da célula bacteriana, que podem agir sobre o epitélio intestinal, produzindo inflamação. As proteases podem contribuir para a patogenicidade causando danos diretos nos tecidos ou aumentando a capacidade de invasão (Sakai, 1985a e b). Endotoxina é o lipopolissacarídeo componente da membrana externa de muitos patógenos Gram-negativos, e tóxico para 
humanos e várias espéices de animais. As hemaglutininas são parte da região superficial da célula bacteriana que permite a sua ligação aos grupos receptores dos eritrócitos (Cahill, 1990).

Um fator dermonecrótico observado na pele de coelhos permitiu a diferenciação entre A. hidrophila e A. sobria (Olivier et al., 1981). Linhagens dermonecróticas de A. hidrophila causaram hemólise em placas contendo sangue de carneiro quando incubadas a $10^{\circ} \mathrm{C}$ e a $30^{\circ} \mathrm{C}$, enquanto A. sobria foram hemolíticas apenas a $30^{\circ} \mathrm{C}$. Todas as linhagens de A. sobria e $72 \%$ das linhagens de A. hydrophila foram positivas para a produção de enterotoxina.

Estudos sobre a correlação entre a produção de toxinas extracelulares e hemolisinas com a patogenicidade em Aeromonas foram realizados por vários autores (Hsu et al., 1981; Allan \& Stevenson, 1981; Thune et al., 1982a). Thune et al. (1986) não encontraram correlação entre a produção de $\beta$-hemolisina e a patogenicidade, assim como Chabot \& Thune (1991), após caracterizarem três proteases, não encontraram correlação entre a produção qualitativa e quantitativa de protease e a virulência em alevinos de bagre do canal, Ictalurus punctatus. Shotts et al. (1985) encontraram apenas que a produção de elastase exibiu uma correlação positiva com a virulência.

Experimentalmente, a presença de uma camada-S na superfície das células foi fortemente correlacionada com virulência; $95 \%$ dos isolamentos feitos em surtos epidemiológicos foram também associados à presença de uma camada-S (Thune et al., 1986). A camada-S é uma estrutura composta por proteínas ou glicoproteínas ligadas à parede celular bacteriana cujas funções são de servir como reservatório de água e nutrientes, aumentar a aderência à superfícies através da formação de biofilmes e do poder infectante, aumentar a capacidade invasiva das bactérias patogênicas que escapam mais facilmente à ação dos fagócitos e aumentar a resistência microbiana a biocidas (Carvalhal \& Alterthum, 1999). Em estudos sobre fatores de virulência, envolvendo as proteases e outras exotoxinas, em infecções causadas por Aeromonas móveis, Shotts et al. (1985) e Del Corral et al. (1990) verificaram a capacidade das células bacterianas aderirem aos eritrócitos, baseados na hipótese de que a habilidade para aderir às células 
do hospedeiro é um pré-requisito para a infecção. Estes autores concluíram que a habilidade de uma determinada linhagem produzir doença, não estava diretamente relacionada a sua capacidade de aderência. A doença pode estar relacionada a múltiplos marcadores fisiológicos e biológicos.

Estudando a patogenicidade de isolados de Aeromonas a partir de água doce e de peixes, Wakabayashi et al. (1981) deteminaram a virulência desta bactéria injetando suspensões bacterianas em bagres japoneses de água doce e examinaram a toxicidade de culturas e extratos celulares por ultra-som. As linhagens ditas virulentas, produziram inchaço e necrose no local de aplicação da injeção intra muscular (i.m.). A maioria das linhagens virulentas eram A. hydrohila biovar hydrophila, e estas linhagens produziram hemorragia na cavidade abdominal após aplicação por via intra peritoneal (i.p.). Os extratos por ultra-som de A. hydrophila biovar hydrophila causaram protuberância das escamas e exoftalmia nos peixes e, estatisticamente, apresentaram maior atividade proteolítica que outras linhagens. A maioria dos isolados estudados produziu hemolisina, protease, lecitinase, lipase e DNAse.

$\mathrm{O}$ efeito do produto extracelular (ECP) gerado por A. hydrophila foi também examinado em juvenis de bagre do canal por Thune et al. (1982b), que demonstraram que o concentrado de uma cultura filtrada pode ser letal para peixes, causando sinais clínicos característicos das infecções por A. hydrophila. Também foi extraída uma endotoxina, mas esta não apresentou efeito letal quando aplicada nos animais por via i.m. Após inativação do ECP não foram registradas casualidades, apesar do efeito ter sido suficiente para indicar a presença de um componente letal termo-estável.

Em outro trabalho, Kanai \& Wakabayashi (1984) apresentaram novas evidências sobre a capacidade letal das proteases. Após isolar uma linhagem de $A$. hydrophila do intestino de enguias doentes, uma protease foi purificada e mostrou-se não somente letal para carpas, como também dermonecrótica, quando injetada na pele de porquinhos-da-índia. Esta protease permaneceu estável a $50^{\circ} \mathrm{C}$.

Estudos feitos por Nieto \& Ellis (1986) demonstram existirem consideráveis diferenças entre as proteases extracelulares produzidas por diferentes linhagens de $A$. 
hydrophila. Na revisão feita por Cahill (1990), conclui-se que os mecanismos de virulência em Aeromonas móveis diferem entre os animais pecilotérmicos e homeotérmicos. As proteases - mistura de enzimas que degradam proteínas - são mais importantes na patogenicidade em peixes, que os fatores hemolíticos e enterotóxicos associados com as doenças humanas, apesar de linhagens isoladas tanto de peixes quanto de humanos, produzirem uma série de ECP biologicamente ativos. Na presença de hospedeiros suscetíveis, estes potenciais fatores de virulência associados à Aeromonas móveis, fornecem a estes organismos a habilidade para agir como patógenos oportunistas. Por esta razão, novos estudos são necessários para determinar as condições sob as quais estes fatores de virulência são produzidos e afetam os hospedeiros in vivo.

\subsection{Sinais clínicos associados às Aeromonas móveis}

As Aeromonas têm sido isoladas não só de peixes, como também de sapos (Gibbs, 1963), cobras (Mead, 1969), camarões de água doce (De Figueiredo \& Plumb 1971) e jacarés (Shotts et al. 1972). Além disso, Aeromonas são contaminantes comuns de peixes e frutos do mar e estão presentes em água potável clorada e não clorada (Hänninen et al., 1997). Assim como em peixes, o envolvimento de Aeromonas em doenças humanas é geralmente associado a outras condições, e sua patogenicidade parece estar relacionada com estresse ou hospedeiros já debilitados. Em humanos, as infecções causadas por Aeromonas estão associadas com oftalmites, ulcerações, infecções e feridas na pele, meningites e septicemia. Em peixes, o principal aspecto da patogênese em todas as infecções causadas por esta bactéria é a disseminação generalizada na forma de septicemia, seguida da elaboração de toxinas, necrose de tecidos e septicemia hemorrágica (Dean \& Tost,1967; Ketover et al.,1973; Joseph et al., 1979 e Quadri et al., 1976).

Os peixes doentes e infectados por A. hydrophila apresentam hemorragias cutâneas nas madadeiras e na superfície do corpo, sendo tal condição geralmente referida como "red fin disease" (Hoshina, 1962). A bactéria se multiplica dentro do intestino, 
causando um catarro mucoso-descamativo. Os metabólitos tóxicos de A. hydrophila são absorvidos pelo intestino e induzem uma toxemia. Ocorrem ainda hemorragias capilares (petéquias), na derme das nadadeiras, na superfície corpo e na submucosa do estômago, com degeneração das células hepáticas e do epitélio dos túbulos renais, causando destruição dos glomérulos e acúmulo de exudato serofibrinoso no tecido hematopoético (Myiazaki \& Jo, 1985; Miyazaki \& Kaige, 1985).

A transmissão do agente infeccioso se dá de modo horizontal, estando o mesmo presente na água e no sedimento de fundo dos viveiros, sendo transmitido por descargas do trato intestinal dos peixes e lesões externas na pele. A doença ocorre com mais frequiência em águas quentes que contenham grande quantidade de material orgânico em associação com fatores estressantes. Estes incluem altas densidades de estocagem, temperatura elevada, mudanças bruscas de temperatura, traumatismos decorrentes de manejo, transferência de peixes e baixos níveis de oxigênio, condição nutricional deficiente e infecções por fungos ou parasitas que contribuem para as mudanças fisiológicas e aumento da suscetibilidade a infecção. Os sinais clínicos característicos são hemorragias ao longo do corpo e orifícios e nas superfícies internas. Rins friáveis e, em casos sub-agudos e crônicos, erosões necróticas e úlceras tornam-se evidentes externamente. Ocorrem necroses do tecido hematopoiético dos rins e baço e necroses locais no coração, fígado, pâncreas e musculatura (Roberts, 1978; Roberts, 1993; Aoki, 1999).

\subsection{O controle das infecções causadas por Aeromonas móveis}

O controle das infecções causadas por A. hydrophila está ligado ao controle de fatores que facilitam a invasão dos hospedeiros. Quando há um surto de doença, especialmente em sistemas de produção de peixes, geralmente não é possível determinar o principal fator estressante ou as fontes de infecções primárias, nem é possível modificar o fluxo de água ou a densidade do estoque. Assim, em geral o tratamento aplicado envolve o uso de antibióticos orais. A quimioterapia em infecções de $A$. 
hydrophila depende da extensão do surto e da regulamentação específica para o uso de medicamentos. Segundo a literatura especializada, sulfamerazine, oxitetraciclina, cloranfenicol e nifurpirinol têm sido usados misturados à ração (Seaman, 1951; Meyer, 1964; Fijan et al., 1976) e geralmente são eficazes no caso de peixes que ainda estão se alimentando, mas como em qualquer tratamento por via oral, peixes severamente afetados acabam não recebendo o tratamento devido ao apetite reduzido. Diversos estudos demonstram que isolados de A. hydrophila apresentam-se sensíveis aos antibióticos cloranfenicol, florfenicol, tetraciclina, sulfonamida, derivados nitrofuranos e ácidos piridonecarboxílicos (Aoki e Egusa, 1971; Endo et al., 1973; Katae et al., 1979; Fukui et al., 1987). Em tratamentos por via oral, os melhores resultados observados envolvem os antibióticos análogos fluorados e os derivados das tetraciclinas, nitrofuranos, sulfonamidas e ácidos piridonecarboxílicos (Austin e Austin, 1987). Okamoto (1992) relata que no Japão o uso de cloranfenicol e a maioria dos derivados nitrofuranos está restrito desde 1983. Na realidade, na lista de antibióticos que podem ser usados na aqüicultura japonesa apresentada por Kusuda e Kawai (1998), o único derivado nitrofurano relacionado é o nifurstirenato, na forma de sal de sódio.

O principal problema envolvendo o uso de antibióticos no tratamento contra A. hydrophila, assim como na maioria das infecções bacterianas, é o desenvolvimento da resistência a antibióticos (Aoki \& Egusa, 1971; Mitchell \& Plumb, 1980), geralmente relacionada aos plasmídeos (Chang \& Bolton, 1987; Ansary et al., 1992). O uso intensivo de antibióticos na aqüicultura japonesa gerou linhagens resistentes de $A$. hydrophila, registradas pela primeira vez em 1971 em fazendas de enguias de água doce. Linhagens resistentes contendo o plasmídeo $\mathrm{R}$ transferível, encontram-se atualmente distribuídas em fazendas de peixes marinhos e de água doce por todo o Japão e já são vários os casos de registro e isolamento de linhagens de A. hydrophila resistentes a medicamentos na França, Irlanda, Malásia, Taiwan, Estados Unidos e Tailândia (Aoki, 1999).

Aoki (1988) demonstrou que linhagens de A. hydrophila que continham plasmídeos $\mathrm{R}$, apresentavam estruturas de DNA idênticas e estavam largamente distribuídas em fazendas de peixes por diversas áreas geográficas. Son et al. (1997) 
registraram que a ocorrência de linhagens de A. hydrophila isoladas de Tilapia mosssambica resistentes a diversos antibióticos em sistemas de produção comerciais na Malásia, era correlacionada à presença e capacidade de transferência dos plasmídeos R.

Segundo Trabulsi et al. (1999) a maioria das Aeromonas são resistentes à penicilina, ampicilina e carbenicilina. Em geral são sensíveis às cefalosporinas de segunda e terceira geração, aos aminoglicosídeos, ao cloranfenicol, ao sulfametoxazoltrimetoprim e às quinolonas. Os animais aquátios mantidos em confinamento são tratados com grande variedade de compostos antimicrobianos e produtos químicos, e o seu uso cada vez mais intensivo como aditivos alimentares ou pela administração direta para prevenir ou tratar doenças, resultou em aumento do número de cepas bacterianas resistentes às drogas (Aoki et al., 1971; Son et al., 1997).

A vacinação é um método alternativo de profilaxia, já caracterizado como uma realidade comercial em doenças como vibriose e doença da boca vermelha (enteric redmouth disease). A diversidade antigênica das Aeromonas móveis sugere que mesmo que seja adquirida resistência a uma linhagem particular, não será garantida proteção contra outras linhagens potencialmente patogênicas do mesmo gênero. Por este motivo, seria necessário o desenvolvimento de vacinas polivalentes como produto comercialmente viável (Roberts, 1993).

Segundo Hästein (1997) uma das maiores vantagens da vacinação contra as doenças bacterianas mais comuns, é a redução no uso de compostos antimicrobianos, apesar de ser necessário o conhecimento sobre medicamentos a serem utilizados no controle de bacterioses para as quais não estão disponíveis vacinas. Diversas estratégias de vacinação têm sido empregadas para evitar a ocorrência de doenças causadas por $A$. hydrophila. Estas incluem desde vacinas preparadas a partir de células mortas por calor, extratos bacterianos inativados por calor ou por formalina, preparações por ultra-som e células vivas. De qualquer maneira, a via oral parece ser a mais simples, barata e ideal para a vacinação em massa de peixes de todos os tamanhos (Azad et al., 1999).

A inconsistência da vacinação oral reside no fato desta apresentar resposta variável em função da degradação digestiva dos antígenos no intestino anterior, antes do 
inóculo vacinal alcançar as áreas responsáveis pela absorção e respostas imunológicas, como o intestino posterior e outros órgãos linfóides (Johnson e Amend, 1983; Rombout et al., 1985). Apesar de eficiente para várias espécies de peixes e com diferentes espécies de bactérias, conforme demonstrado por Ruangpan et al. (1986), o método de vacinação por infiltração hiperosmótica - imersão inicial em solução salina hipertônica - mostra-se ineficiente para tilápias contra linhagens de A. hydrophila.

No Brasil, até o presente, não temos informações detalhadas e conhecimento aprofundado das Aeromonas móveis presentes nos ambientes de produção de peixes. Faz-se, então, necessária a investigação e experimentação envolvendo a identificação primária deste grupo de bactérias potencialmente patogênicas, para que se possa fundamentar estudos de virulência, patogenicidade e vacinas ou drogas para as espécies de peixes de água doce cultivadas comercialmente. 


\section{MATERIAL E MÉTODOS}

\subsection{Origem dos organismos}

Foram estudados isolamentos bacterianos realizados durante a ocorrência de mortandades em diversas regiões do Brasil, pertencentes à coleção de cultura do Laboratório de Piscicultura, do Departamento de Zootecnia da ESALQ-USP e como linhagem de referência, foi utilizada a cepa tipo de Aeromonas hydrophila, obtida da American Type Culture Collection através da Fundação André Tosselo - Campinas, SP. (Tabela 1).

Tabela 1. Isolamentos bacterianos realizados durante epizootias e usados neste estudo.

\begin{tabular}{|c|c|c|}
\hline \multicolumn{2}{|c|}{ Linhagem } & \multirow{2}{*}{$\begin{array}{c}\text { Origem } \\
\text { Surubim, fígado, Sta. Maria de Itabira-MG }\end{array}$} \\
\hline Staphylococcus sp. & LQUSP02 & \\
\hline Plesiomonas shigelloides & LQUSP03 & Surubim, cavidade celomática, Itaporã-MS \\
\hline Plesiomonas shigelloides & LQUSP04 & Surubim, fígado, Itaporã-MS \\
\hline Vibrio sp. & LQUSP05 & Tilápia, fígado, Itacuruba-PE \\
\hline Aeromonas hydrophila & LQUSP13 & Tilápia, fígado, Jaú-SP \\
\hline Aeromonas hydrophila & LQUSP14 & Tilápia, rim, Jaú-SP \\
\hline Aeromonas hydrophila & LQUSP15 & Tilápia, brânquias, Jaú-SP \\
\hline Aeromonas hydrophila & LQUSP16 & Tilápia, fígado, Jaú-SP \\
\hline Aeromonas hydrophila & LQUSP17 & Tilápia, brânquias, Jaú-SP \\
\hline Aeromonas hydrophila & LQUSP18 & Tilápia, fígado, Jaú-SP \\
\hline Aeromonas hydrophila & LQUSP19 & Tilápia, baço, Jaú-SP \\
\hline Aeromonas hydrophila & LQUSP20 & Pacu, brânquias, Piracicaba-SP \\
\hline Plesiomonas shigelloides & LQUSP21 & Pacu, fígado, Piracicaba-SP \\
\hline Aeromonas hydrophila & LQUSP22 & $\mathrm{Pacu}$, rim, Piracicaba-SP \\
\hline Aeromonas hydrophila & LQUSP23 & Pacu, brânquias, Piracicaba-SP \\
\hline Aeromonas hydrophila ${ }^{\mathbf{T}}$ & ATCC7966 & American Type Culture Colection \\
\hline
\end{tabular}


Apartir dos isolados de peixes, foram selecionadas duas linhagens de Aeromonas móveis, de tilápia do Nilo Oreochromis niloticus e de pacu Piaractus mesopotamicus, e uma linhagem de Plesiomonas shigelloides isolada de surubim Pseudoplatystoma corruscans, para a realização de estudos mais detalhados. As linhagens foram preservadas em nitrogênio líquido e as culturas de trabalho mantidas em agar extrato de levedura (YEA) a $28^{\circ} \mathrm{C}$ (Costa et al., 1998b).

\subsection{Caracterização bioquímica}

Os testes bioquímicos realizados foram ferro três-açúcares (TSI) para verificar a produção de ácido sulfídrico $\left(\mathrm{H}_{2} \mathrm{~S}\right)$ a partir de tiosulfato; citrato de Simmon (Simmon, 1926); urease (Christensen, 1946); arginina; lisina; ornitina; produção de indol; vermelho de metila (MR); produção de acetilmetilcarbinol pelo teste de VogesProskauer (VP) (Eddy, 1961); hidrólise de gelatina (Levine \& Carpenter, 1923) e esculina.

A acidificação de carboidratos foi realizada pela incorporação do carboidrato específico $(0,5 \%)$ em caldo vermelho de fenol ("phenol red broth base"), sendo a produção de gás em meio líquido a partir da glucose observada pela incorporação de tubos de Durham invertidos. Para verificar a produção de enzimas extracelulares, os testes de DNAse, amilase e Tween 20 (lipase-esterase) foram utilizados.

A habilidade de crescimento sob condições variadas foi determinada utilizando-se agar cérebro-coração (BH); MacConkey (MAC); Salmonella-Shigella (SS); verde brilhante vermelho fenol lactose sucrose (BPLS); caldo RappaportVassiliadis (RVS); e verde-brilhante bile lactose (BRILA).

Outros testes realizados foram Gram-stain; catalase $\left(3 \% \mathrm{H}_{2} \mathrm{O}_{2}\right)$; oxidase; motilidade e crescimento a $25^{\circ} \mathrm{C}, 37^{\circ} \mathrm{C}$ e a $42^{\circ} \mathrm{C}$; oxidação/fermentação ("glucose motility deep - GMD”) (Plumb \& Bowser, 1983); hemólise (YEA suplementado com 5\% de sangue de coelho); crescimento em caldo YEA suplementado com cloreto de 
sódio $(\mathrm{NaCl})$ a 0\%, 3\%, 6\%, 6,5\% e 7\% e em pH 3 e 10; e teste de hidróxido de potássio para Gram (3\% KOH) (método de não coloração).

\subsection{Antibióticos}

A atividade antimicrobiana de agentes quimioterápicos foi verificada por testes de inibição do crescimento bacteriano. Os padrões de sensibilidade e resistência a antibióticos foram determinados pelo método de difusão em discos de Kirby-Beuer, descrito por Stukus (1997), envolvendo o uso dos seguintes antibióticos: amoxicilina

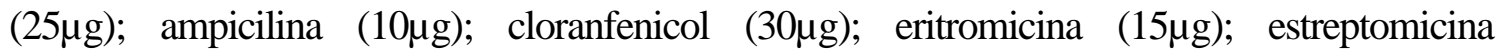
$(10 \mu \mathrm{g})$; gentamicina $(10 \mu \mathrm{g})$; kanamicina $(30 \mu \mathrm{g})$; licomicina $(2 \mu \mathrm{g})$; nitrofurantoina $(300 \mu \mathrm{g})$; norfloxacina $(10 \mu \mathrm{g})$; novobiocina $(30 \mu \mathrm{g})$; oxacilina $(1 \mu \mathrm{g})$; penicilina G (10 UI $=6 \mu \mathrm{g})$; rifampicina $(5 \mu \mathrm{g})$; sulbactam $(10 \mu \mathrm{g})+$ ampicilina $(10 \mu \mathrm{g})$; tetraciclina $(30 \mu \mathrm{g})$; trimetoprim $(1,25 \mu \mathrm{g})+$ sulfametoxazol $(23,75 \mu \mathrm{g})$.

Os discos de papel dos antibióticos foram colocados sobre superfícies de YEA, previamente inoculados com $100 \mu \mathrm{L}$ de suspensão das bactérias em teste, inoculadas em caldo $\mathrm{YE}\left(28^{\circ} \mathrm{C}\right.$ por $\left.24 \mathrm{~h}\right)$. Após incubação das placas contendo os discos de antibióticos a $28^{\circ} \mathrm{C}$ por uma noite, procedeu-se à leitura das mesmas medindo-se, em milímetros, o diâmetro da zona de inibição do crescimento das colônias. O desempenho das linhagens com relação ao antibiótico oxitetraciclina, foi verificado pela

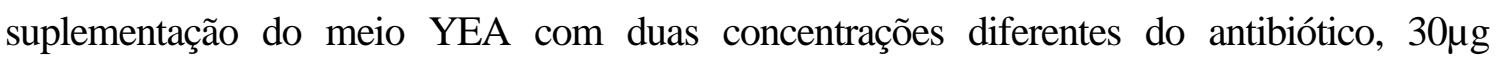
$\mathrm{mL}^{-1}$ e $100 \mu \mathrm{g} \mathrm{mL} \mathrm{m}^{-1}$.

\subsection{Análise de proteínas totais}

A separação analítica das proteínas celulares das linhagens bacterianas estudadas foi realizada através do método de SDS-PAGE (Laemmli, 1970), em gel de poliacrilamida a 12,5\% com sistema tampão descontínuo. Após a eletroforese, as proteínas no gel foram coradas com PhastGel Blue $\mathrm{R}^{\circledR}$ (Pharmacia Biotech) e armazenadas em solução de metanol e ácido acético para posterior fotografia das bandas. 
Antes da realização da eletroforese, $50 \mu \mathrm{L}$ de suspensão bacteriana de cada linhagem em estudo foi inoculada em placas de agar suplementadas com glucose (Garrote et al., 1992) ou YEA, deixadas secar e incubadas a $28^{\circ} \mathrm{C}$ por $40 \mathrm{~h}$. Em seguida, as células foram lavadas das placas com PBS $(\mathrm{pH} 7,2)$, recolhidas por centrifugação (10.000 rpm, $10 \mathrm{~min}$ ) e diluídas para a concentração de $0,1 \mathrm{~g} \mathrm{~mL}^{-1}$ em PBS. Para o rompimento das células bacterianas as mesmas foram expostas a um aparelho de ultrasom $(27 \mathrm{~W} ; 20 \mathrm{~min})$ sob refrigeração. Após o rompimento das células, foi adicionado ao lisado $0,02 \%$ de azida sódica como conservante e posteriormente foi feita diálise das amostras.

\subsection{Preparação dos antígenos}

Os antígenos LQUSP03, LQUSP15, LQUSP22 e ATCC7966 foram preparados de acordo com Plumb e Bowser (1983), com modificações. As bactérias foram altivadas em placas contendo YEA a $28^{\circ} \mathrm{C}$ por $24 \mathrm{~h}$. As placas foram lavadas com PBS (pH 7,2) e as células centrifugadas a $10.000 \mathrm{rpm}$ por dez minutos e lavadas cinco vezes em PBS. Em seguida as células foram inativadas a $56^{\circ} \mathrm{C}$ em banho Dubnoff por uma hora. Foi adicionado $0,1 \%$ de formalina como conservante e os antígenos foram mantidos a $4^{\circ} \mathrm{C}$ até serem utilizados.

\subsection{Preparação dos anti-soros}

Os anti-soros utilizados neste estudo foram preparados pela imunização de coelhos brancos da raça Norfolk-Botucatu, com células bacterianas das linhagens LQUSP03, LQUSP15, LQUSP22 e ATCC7966, neutralizadas com formalina. O antígeno foi diluído na proporção 1:10 com PBS (pH 7,2), misturado com o adjuvante completo de Freund (FCA) na proporção 1:1. Em seguida, $2 \mathrm{~mL}$ da mistura (5mg de antígeno $\mathrm{mL}^{-1}$ ) foram injetados via subcutânea, por duas vezes, com intervalo de duas semanas, no dorso dos animais. Na quarta semana, $1,0 \mathrm{~mL}$ do antígeno $\left(10 \mathrm{mg} \mathrm{mL}^{-1}\right)$ foi 
injetado via intravenosa na orelha dos coelhos e após uma semana a titulação de aglutinação do soro foi testada.

O sangue dos animais foi recolhido seis semanas após a primeira injeção e deixado coagular por uma hora à temperatura ambiente. A parte líquida foi transferida para um novo recipiente, colocado sob refrigeração por uma noite e o soro recolhido por centrifugação $(8.000 \mathrm{rpm}, 15 \mathrm{~min})$. Em seguida, as células foram inativadas em banho Dubnoff a $56^{\circ} \mathrm{C}$ e o soro foi dividido em pequenas alíquotas e armazenado em supercongelador $\left(20^{\circ} \mathrm{C}\right)$ até seu uso. O título de aglutinação dos anti-soros para definir o momento de sacrificar os coelhos situou-se entre 512 e 1024 , aproximadamente $10^{-2}$ e $10^{-3}$, respectivamente.

\subsection{Ensaio sorológico - Aglutinação}

A relação sorológica entre as linhagens estudadas foi determinada por aglutinação em lâminas de vidro de acordo com os procedimentos básicos sugeridos por Sørensen \& Larsen (1986) e Santos et al. (1996), e pela técnica de microplacas (Toranzo at al., 1987; Roberson, 1990). Os testes de aglutinação em lâminas foram conduzidos através da mistura de uma gota de cada suspensão de antígeno $\left(10^{9}\right.$ células $\mathrm{mL}^{-1}$, padrão McFarland $\mathrm{n}^{\mathrm{o}}$ 3) com uma gota do anti-soro produzido sobre uma lâmina de vidro. Aglutinações visíveis e imediatas foram registradas como positivas. Foi registrada como negativa a não observação de reação de aglutinação após um a dois minutos.

Para a aglutinação em microplacas de 96 poços, a concentração de cada antígeno foi padronizada para $5 \mathrm{mg} \mathrm{mL}^{-1}$ e a titulação do anti-soro em PBS começou a partir de uma diluição dupla. A cada poço foram adicionados $25 \mu \mathrm{L}$ de PBS (pH 7,2) e no primeiro poço de cada fileira foram adicionados $25 \mu \mathrm{L}$ de cada anti-soro. O PBS e o anti-soro foram misturados e $25 \mu \mathrm{L}$ da mistura foram transferidos para o poço seguinte, e assim sucessivamente, com exceção do último poço da fileira, que funcionou como controle. Em seguida foram adicionados $25 \mu \mathrm{L}$ do antígeno respectivo em cada fileira de poços. Antígeno e anti-soro foram misturados, incubados a $37^{\circ} \mathrm{C}$ por duas horas e, posteriormente, mantidos sob refrigeração por uma noite para leitura da titulação. 


\subsection{Extração de antígenos celulares}

A extração de antígenos celulares das linhagens LQUSP03, LQUSP15, LQUSP22 e ATCC7966 foi feita de acordo com a metodologia de extração de antígenos superficiais de células de Escherichia coli (Ørskov \& Ørskov, 1970), com modificações. As bactérias foram cultivadas a $28^{\circ} \mathrm{C}$ por $48 \mathrm{~h}$ em placas contendo YEA, posteriormente lavadas com PBS (pH 7,2), e as células recolhidas por centrifugação (10.000 rpm, 10min). As células foram, em seguida, suspensas em PBS na concentração de $100 \mathrm{mg}$ $\mathrm{mL}^{-1}$ e os antígenos celulares extraídos pelo aquecimento da suspensão celular bacteriana a $60^{\circ} \mathrm{C}$ ou $100^{\circ} \mathrm{C}$ por 30 minutos. Por centrifugação $(10.000 \mathrm{rpm} / 10 \mathrm{~min})$, recolheu-se o sobrenadante, denominando-os extrato $60^{\circ} \mathrm{C}$ e extrato $100^{\circ} \mathrm{C}$, respectivamente. Os extratos foram mantidos a $4^{\circ} \mathrm{C}$ até seu uso.

\subsection{Imunodifusão}

Para a demonstração da micropreciptação e migração do complexo antígenoanticorpo e o estudo da relação sorológica entre as linhagens LQUSP03, LQUSP15, LQUSP22 e ATCC7966, foi utilizada a técnica de dupla imunodifusão de Ouchterlony (Ouchterlony, 1968; Gerhardt et al., 1994; Stukus, 1997). Os anti-soros utilizados foram Anti-LQUSP03, Anti-LQUSP15, Anti-LQUSP22 e Anti- ATCC7966, previamente produzidos em coelhos.

A imunodifusão teve lugar em $1 \%$ agarose em PBS (pH 7,2) contendo 0,01\% azida sódica como preservativo, em lâminas de vidro $(5,5 \mathrm{~cm} \times 8,5 \mathrm{~cm})$. A quantidade de agarose utilizada para recobrir as lâminas foi de $0,18 \mathrm{~mL} \cdot \mathrm{cm}^{-2}$. Após a solidificação, foram feitas três perfurações no agar e o poço central da placa, preenchido por $15 \mathrm{i} \mathrm{L}$ de antisoro, enquanto os poços adjacentes foram preenchidos com $15 \mathrm{i} \mathrm{L}$ $\left(10 \mathrm{mg} \mathrm{mL}^{-1}\right)$ de cada antígeno celular bacteriano extraído a $60^{\circ} \mathrm{C}$ e a $100^{\circ} \mathrm{C}$. As lâminas foram mantidas em câmara úmida a temperatura ambiente por 24 a $72 \mathrm{~h}$ e observadas diariamente, sendo as bandas de precipitação registradas por desenhos e fotografias. 


\section{RESULTADOS}

As características bioquímicas e enzimáticas das linhagens estudadas encontram-se relacionadas na Tabela 2. Todos os isolamentos foram testados para cada característica. Os resultados bioquímicos das três linhagens estudadas foram comparados com os resultados apresentados pelo espécime tipo de A. hydrophila, ATCC7966.

As linhagens LQUSP03, LQUSP15 e LQUSP22 são organismos Gramnegativos em formato de haste. $\mathrm{O}$ espécime tipo para A. hydrophila apresentou motilidade a $25^{\circ} \mathrm{C}$ mas não a $37^{\circ} \mathrm{C}$. As três linhagens estudadas apresentaram motilidade a $25^{\circ} \mathrm{C}$. A $37^{\circ} \mathrm{C}$ as linhagens LQUSP03 e LQUSP22 mostraram-se móveis, enquanto a linhagem LQUSP15 não apresentou motilidade.

Todas as linhagens isoladas de peixes e o espécime tipo são bactérias fermentativas, produziram indol e arginina decarboxilase, não produziram ácido sulfídrico nem urease e o teste de vermelho de metila (MR) resultou negativo. Foi produzido ácido a partir de galactose, glucose, maltose e trealose. Os testes de catalase e oxidase foram positivos e houve crescimento bacteriano a $25^{\circ} \mathrm{C}$, a $37^{\circ} \mathrm{C}$ e a $42^{\circ} \mathrm{C}$ e em pH 3 e pH 10.

As linhagens apresentaram crescimento a 0 e $3 \%$, mas não a $6 \%, 6,5 \%$ ou $7 \% \mathrm{NaCl}$. Exceto para o caldo Rappaport-Vassiliadis (RVS), os resultados referentes à habilidade de crescimento das linhagens isoladas de diferentes espécies de peixes, observada nos meios agar previamente descritos, foi positiva, assim como os resultados observados para o espécime tipo de A. hydrophila, ATCC7966.

A linhagem LQUSP03 difere do espécime tipo de A. hydrophila, ATCC7966, em alguns dos demais testes bioquímicos realizados, com a exceção de também não ser capaz de produzir ácido a partir de adonitol, dulcitol, lactose, salicina, 
sorbitol nem xilose e não hidrolisar esculina. Assim como as linhagens LQUSP15 e LQUSP22, também não produziu ácido a partir do carboidrato rafinose.

As linhagens LQUSP22 e LQUSP03 apresentam motilidade a $37^{\circ} \mathrm{C}$ e não são capazes de utilizar o carboidrato arabinose, porém a linhagem LQUSP15 não apresenta motilidade a $37^{\circ} \mathrm{C}$; utiliza arabinose e esculina, diferindo da linhagem LQUSP22. Nas demais características bioquímicas, as linhagens LQUSP15 e LQUSP22 apresentaram resultados idênticos aos observados para o espécime tipo de A. hydrophila ATCC7966, tais como a produção de gás a partir de glucose, utilização de citrato e produção de acetilmetilcarbinol (VP), amilase, lipase, deoxiribonuclease e hemolisina e a não decarboxilação de lisina e ornitina, nem a hidrólise de gelatina. Semelhante à linhagem ATCC7966, as linhagens isoladas de tilápia e pacu, LQUSP15 e LQUSP22, respectivamente, fermentaram amido, dextrina, frutose, glicerina, manitol, manose e sucrose, mas não inositol, o que é característico das bactérias do Gênero Aeromonas. 
Tabela 2. Características bioquímicas dos organismos estudados.

\begin{tabular}{|c|c|c|c|c|}
\hline \multicolumn{5}{|c|}{ Organismos } \\
\hline Características & LQUSP03 & LQUSP15 & LQUSP22 & $\mathrm{ATCC7966}^{\mathrm{T}}$ \\
\hline Gram-stain & - & - & - & - \\
\hline $3 \% \mathrm{KOH}$ & - & - & - & - \\
\hline Catalase & + & + & + & + \\
\hline Oxidase & + & + & + & + \\
\hline Motilidade a $25^{\circ} \mathrm{C}$ & + & + & + & + \\
\hline Motilidade a $37^{\circ} \mathrm{C}$ & + & - & + & - \\
\hline $\mathrm{O} / \mathrm{F}$ & $\mathbf{F}$ & $\mathbf{F}$ & $\mathbf{F}$ & $\mathbf{F}$ \\
\hline Crescimento a $25^{\circ} \mathrm{C}$ & + & + & + & + \\
\hline Crescimento a $37^{\circ} \mathrm{C}$ & + & + & + & + \\
\hline Crescimento a $42^{\circ} \mathrm{C}$ & + & + & + & + \\
\hline Citrato de Simmom & - & + & + & + \\
\hline $\mathrm{H}_{2} \mathrm{~S}$ & - & - & - & - \\
\hline Urease & - & - & - & - \\
\hline Indol & + & + & + & + \\
\hline MR & - & - & - & - \\
\hline VP & - & + & + & + \\
\hline Ácido a partir de & & & & \\
\hline Adonitol & - & - & - & - \\
\hline Amido & - & + & + & + \\
\hline Arabinose & - & + & - & + \\
\hline Dextrina & - & + & + & + \\
\hline Dulcitol & - & - & - & - \\
\hline Frutose & - & + & + & + \\
\hline Galactose & + & + & + & + \\
\hline Glicerina & - & + & + & + \\
\hline Glucose & + & + & + & + \\
\hline Inositol & + & - & - & - \\
\hline Lactose & - & - & - & - \\
\hline Maltose & + & + & + & + \\
\hline Manitol & - & + & + & + \\
\hline Manose & - & + & + & + \\
\hline Rafinose & - & - & - & + \\
\hline Salicina & - & + & + & - \\
\hline Sorbitol & - & - & - & - \\
\hline Sucrose & - & + & + & + \\
\hline Trealose & + & + & + & + \\
\hline Xilose & - & - & - & - \\
\hline
\end{tabular}


Tabela 2. Características bioquímicas dos organismos estudados. Continuação.

\begin{tabular}{|c|c|c|c|c|}
\hline \multicolumn{5}{|c|}{ Organismos } \\
\hline Características & LQUSP03 & LQUSP15 & LQUSP22 & $\mathrm{ATCC7966}^{\mathrm{T}}$ \\
\hline DNAse & - & + & + & + \\
\hline Amilase & - & + & + & + \\
\hline Tween 20 & - & + & + & + \\
\hline Hemólise & - & + & + & + \\
\hline Decarboxilação de & & & & \\
\hline Arginina & + & + & + & + \\
\hline Lisina & + & - & - & - \\
\hline Ornitina & + & - & - & - \\
\hline Hidrólise de & & & & \\
\hline Gelatina & + & - & - & - \\
\hline Esculina & - & + & - & - \\
\hline Gás a partir de & & & & \\
\hline Glucose & - & + & + & + \\
\hline Crescimento a & & & & \\
\hline $0 \% \mathrm{NaCl}$ & + & + & + & + \\
\hline $3 \% \mathrm{NaCl}$ & + & + & + & + \\
\hline $6 \% \mathrm{NaCl}$ & - & - & - & - \\
\hline $6,5 \% \mathrm{NaCl}$ & - & - & - & - \\
\hline $7 \% \mathrm{NaCl}$ & - & - & - & - \\
\hline $\mathrm{pH} 3$ & + & + & + & + \\
\hline $\mathrm{pH} 10$ & + & + & + & + \\
\hline Crescimento em & & & & \\
\hline $\mathrm{BH}$ & + & + & + & + \\
\hline BPLS & + & + & + & + \\
\hline BRILA & + & + & + & + \\
\hline MAC & + & + & + & + \\
\hline RVS & - & - & - & - \\
\hline SS & + & + & + & + \\
\hline
\end{tabular}

${ }^{\mathbf{T}}$ Espécime tipo 
A sensibilidade de cada linhagem estudada frente aos agentes antimicrobianos em meio YEA, está listada na Tabela 3 e graficamente representada na Figura 1. A linhagem LQUSP03 apresentou resistência aos antibióticos ampicilina, amoxicilina, gentamicina, lincomicina, oxacilina, penicilina, rifampicina, trimetoprim+sulfametoxazol e tetraciclina, e foi sensível aos demais antibióticos testados.

A linhagem LQUSP15 foi resistente a ampicilina, amoxicilina, lincomicina, novobiocina, oxacilina, penicilina, rifampicina e trimetoprim+sulfametoxazol. Apresentou-se pouco sensível aos antibióticos eritromicina, kanamicina e sulbactam+ampicilina e para os demais antibióticos foi sensível.

A linhagem LQUSP22 apresentou-se resistente aos antibióticos ampicilina, amoxicilina, gentamicina, lincomicina, novobiocina, oxacilina, penicilina, rifampicina, sulbactam+ampicilina, trimetoprim+sulfametoxazol e tetraciclina, e sensível para os outros antibióticos testados. O espécime tipo ATCC7966 foi resistente aos antibióticos ampicilina, amoxicilina, lincomicina, novobiocina, oxacilina, penicilina, rifampicina, sulbactam+ampicilina e trimetoprim+sulfametoxazol, e sensível para os demais antibióticos.

As linhagens LQUSP03 e LQUSP22 apresentaram crescimento nas placas suplementadas com o antibiótico oxitetraciclina nas concentrações de $30 \mu \mathrm{g} \cdot \mathrm{mL}^{-1} \mathrm{e}$

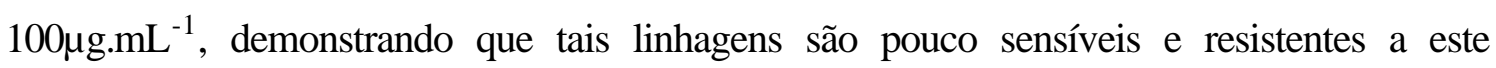
antibiótico, independente das concentrações testadas. As linhagens LQUSP15 e ATCC7966 não apresentaram crescimento bacteriano nas placas que continham o antibiótico oxitetraciclina nas duas concentrações supra-citadas. 
Tabela 3. Perfil de sensibilidade/resistência das linhagens bacterianas estudadas. Ssensível; R-resistente; I-intermediário; AX 25, amoxicilina $(25 \mu \mathrm{g}) ; \mathrm{AM} 10$,

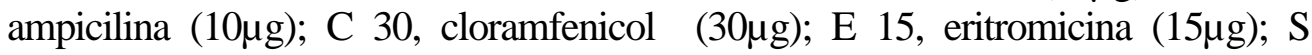
10 , estreptomicina $(10 \mu \mathrm{g}) ; \mathrm{CN} 10$, gentamicina $(10 \mu \mathrm{g}) ; \mathrm{K} 10$, kanamicina $(30 \mu \mathrm{g}) ; \mathrm{L} 2$, lincomicina $(2 \mu \mathrm{g})$; F 300, nitrofurantoina $(300 \mu \mathrm{g})$; NOR 10, norfloxacina $(10 \mu \mathrm{g})$; NV 30, novobiocina $(30 \mu \mathrm{g})$; OX 1, oxacilina $(1 \mu \mathrm{g}) ; \mathrm{P} 6$, penicilina $\mathrm{G}(6 \mu \mathrm{g})$; RA 5, rifampicina $(5 \mu \mathrm{g})$; SAM 10, sulbactam + ampicilina $(10 \mu \mathrm{g}+10 \mu \mathrm{g}) ; \quad \mathrm{TE} 30$, tetraciclina $(30 \mu \mathrm{g}) ; \quad$ SXT 25 , trimetoprim + sulphamethoxazol $(1,25 \mu \mathrm{g}+23,75 \mu \mathrm{g})$.

\begin{tabular}{lcccc}
\hline & LQUSP03 & LQUSP15 & LQUSP22 & ATCC7966 \\
\hline AX 25 & $\mathrm{R}$ & $\mathrm{R}$ & $\mathrm{R}$ & $\mathrm{R}$ \\
AM 10 & $\mathrm{R}$ & $\mathrm{R}$ & $\mathrm{R}$ & $\mathrm{R}$ \\
C 30 & $\mathrm{S}$ & $\mathrm{S}$ & $\mathrm{S}$ & $\mathrm{S}$ \\
E 15 & $\mathrm{S}$ & $\mathrm{I}$ & $\mathrm{S}$ & $\mathrm{S}$ \\
S 10 & $\mathrm{S}$ & $\mathrm{S}$ & $\mathrm{S}$ & $\mathrm{S}$ \\
CN 10 & $\mathrm{R}$ & $\mathrm{S}$ & $\mathrm{R}$ & $\mathrm{S}$ \\
K 10 & $\mathrm{S}$ & $\mathrm{I}$ & $\mathrm{S}$ & $\mathrm{S}$ \\
L 2 & $\mathrm{R}$ & $\mathrm{R}$ & $\mathrm{R}$ & $\mathrm{R}$ \\
F 300 & $\mathrm{S}$ & $\mathrm{S}$ & $\mathrm{S}$ & $\mathrm{S}$ \\
NOR 10 & $\mathrm{S}$ & $\mathrm{S}$ & $\mathrm{S}$ & $\mathrm{S}$ \\
NV 30 & $\mathrm{S}$ & $\mathrm{R}$ & $\mathrm{R}$ & $\mathrm{R}$ \\
OX 1 & $\mathrm{R}$ & $\mathrm{R}$ & $\mathrm{R}$ & $\mathrm{R}$ \\
P 6 & $\mathrm{R}$ & $\mathrm{R}$ & $\mathrm{R}$ & $\mathrm{R}$ \\
RA 5 & $\mathrm{R}$ & $\mathrm{S}$ & $\mathrm{S}$ & $\mathrm{R}$ \\
SAM 10 & $\mathrm{~S}$ & $\mathrm{I}$ & $\mathrm{R}$ & $\mathrm{R}$ \\
TE 30 & $\mathrm{R}$ & $\mathrm{S}$ & $\mathrm{R}$ & $\mathrm{S}$ \\
SXT 25 & $\mathrm{R}$ & $\mathrm{R}$ & $\mathrm{R}$ & $\mathrm{R}$ \\
\hline
\end{tabular}


a)

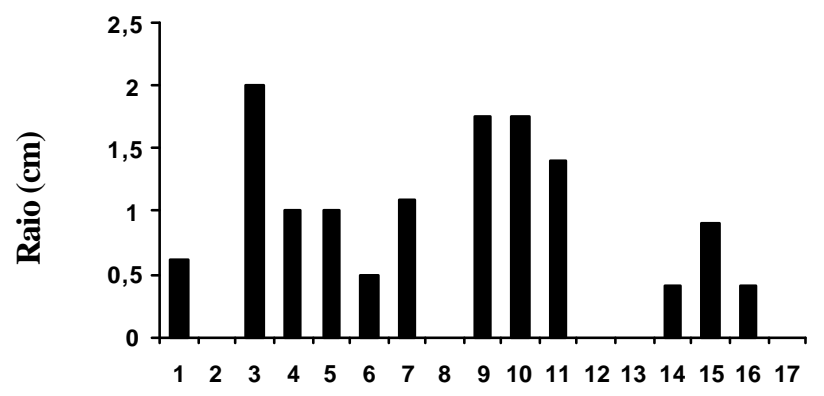

Antibióticos

c)

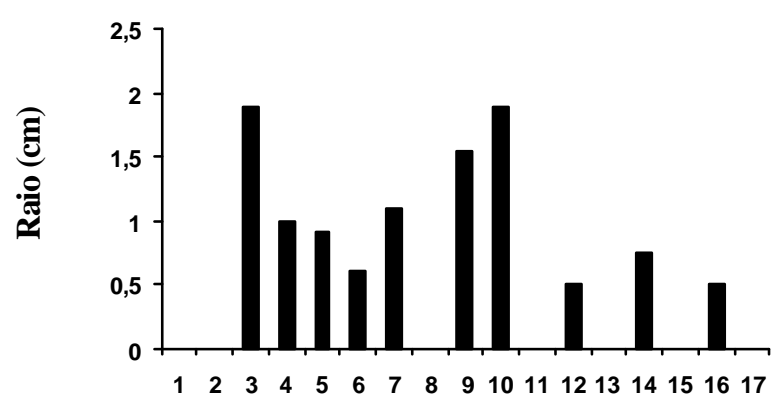

Antibióticos b)

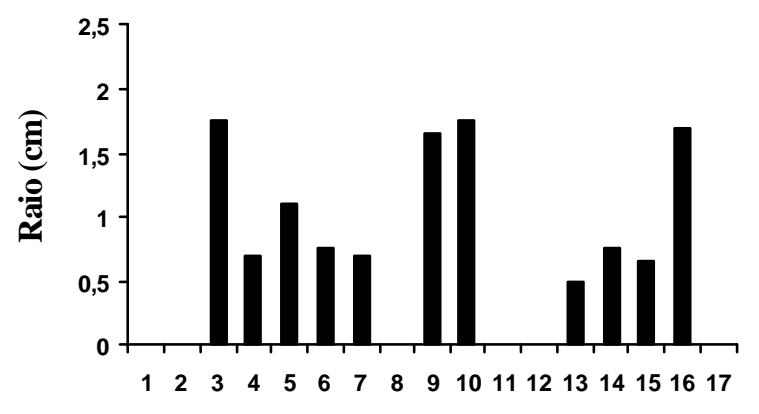

Antibióticos

d)

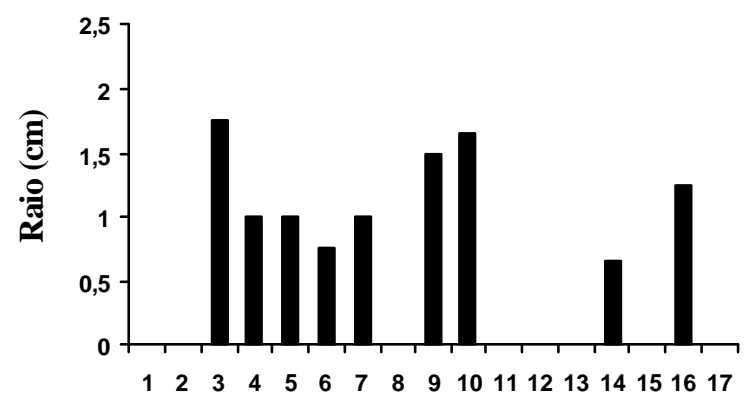

Antibióticos

Figura 1 - Sensibilidade a antibióticos demonstrada pelas linhagens a) LQUSP03, b) LQUSP15, c) LQUSP22 e d)ATCC7966, expostas a 17 antibióticos de várias concentrações ( $\mu \mathrm{g} /$ disco):
1. Amoxicilina $(25 \mu \mathrm{g})$
2. Ampicilina $(10 \mu \mathrm{g})$
3. Cloranfenicol $(30 \mu \mathrm{g})$
4. Eritromicina $(15 \mu \mathrm{g})$
5. Estreptomicina $(10 \mu \mathrm{g})$
6. Gentamicina $(10 \mu \mathrm{g})$
7. Kanamicina $(30 \mu \mathrm{g})$
8. Lincomicina $(2 \mu \mathrm{g})$
9. Nitrofurantoina $(300 \mu \mathrm{g})$

10. Norfloxacina $(10 \mu \mathrm{g})$

11. Novobiocina $(30 \mu \mathrm{g})$

12. Oxacilina $(1 \mu \mathrm{g})$

13. Penicilina G $(6 \mu \mathrm{g})$

14. Rifampicina $(5 \mu \mathrm{g})$

15. Sulbactam $(10 \mu \mathrm{g})+$ ampicilina $(10 \mu \mathrm{g})$

16. Tetraciclina $(30 \mu \mathrm{g})$

17. Trimetoprim $(1,25 \mu \mathrm{g})+$ sulfametoxazol $(23,75 \mu \mathrm{g})$ 
A aglutinação em lâminas demonstrou que as linhagens podem ser divididas em 4 sorogrupos diferentes, não havendo reação cruzada entre os grupos. Em microplacas, os títulos de aglutinação dos anti-soros para células mortas por formalina e células mortas por calor são mostrados nas Tabelas 4 e 5 , respectivamente. Os testes de aglutinação demonstram que as linhagens podem ser tipificadas.

Quando foram usados os antígenos celulares derivados de células mortas por formalina ("formalin-killed cells"), as linhagens distribuíram-se de maneiras distintas. O isolado de surubim, LQUSP03, apresentou três grupos sorológicos: grupo 1 - o isolado de surubim; gupo 2 - o isolado de tilápia; e grupo 3 - o isolado de pacu e A. hydrophila espécime tipo. A linhagem LQUSP15, isolada de tilápia, formou dois grupos sorológicos: grupo 1 - o isolado de surubim, pacu e A. hydrophila espécime tipo; e grupo 2 - o isolado de tilápia. A linhagem LQUSP22, isolada de pacu formou dois grupos sorológicos: grupo 1 - o isolado de surubim e A. hydrophila espécime tipo; e grupo 2 os isolados de tilápia e pacu. A linhagem de A. hydrophila formou três grupos sorológicos: grupo 1 - o isolado de surubim e pacu; grupo 2 - o isolado de tilápia; e grupo 3 - A. hydrophila espécime tipo (Tabela 4).

Tabela 4. Títulos de aglutinação de anti-soros de A. hydrophila para células mortas por formalina (formalin-killed cells).

\begin{tabular}{lcccc}
\hline & \multicolumn{4}{c}{ Anti-soro } \\
\cline { 2 - 5 } Antígeno & LQUSP03(f) & LQUSP15(f) & LQUSP22(f) & ATCC7966 $^{\mathrm{T}}$ (f) \\
\hline LQUSP03(f) & 4096 & 8 & 8 & 8 \\
LQUSP15(f) & 512 & 131072 & 512 & 512 \\
LQUSP22(f) & 8 & 32 & 128 & 32 \\
ATCC7966 (f) & 32 & 32 & 16 & 4096 \\
\hline
\end{tabular}

$\mathrm{f}=$ "formalin-killed cells"

${ }^{\mathbf{T}}$ Espécime tipo.

Também quando foram usados os antígenos celulares preparados com células mortas por calor ("heat-killed cells"), as linhagens distribuíram-se de maneiras distintas. A linhagem LQUSP03 formou dois grupos sorológicos diferentes: grupo 1 - o isolado de surubim; e grupo 2 - os isolados de tilápia, pacu e A.hydrophila. O isolado de 
surubim, LQUSP15 apresentou dois grupos sorológicos: grupo 1 - os isolados de surubim, pacu e A. hydrophila; e grupo 2 - o isolado de tilápia. A linhagem LQUSP22, isolada de pacu, apresentou dois grupos sorológicos: grupo 1 - os isolados de surubim, tilápia e A. hydrophila; e grupo 2 - o isolado de pacu. A linhagem de A.hydrophila, ATCC7966 formou dois grupos: grupo 1 - os isolados de surubim, tilápia e pacu; e grupo 2 - A. hydrophila espécime tipo (Tabela 5).

Tabela 5. Títulos de aglutinação de anti-soros de A. hydrophila para células mortas por calor (heat-killed cells).

\begin{tabular}{lcccc}
\hline & \multicolumn{4}{c}{ Anti-soro } \\
\cline { 2 - 5 } Antígeno & LQUSP03(f) & LQUSP15(f) & LQUSP22(f) & ATCC7966 (f) $^{\mathrm{T}}$ \\
\hline LQUSP03(h) & 16384 & 64 & 64 & 64 \\
LQUSP15(h) & 16 & 4096 & 64 & 32 \\
LQUSP22(h) & 16 & 128 & 2048 & 64 \\
ATCC7966 $^{\mathrm{T}}(\mathrm{h})$ & 16 & 256 & 256 & 512 \\
\hline
\end{tabular}

$\mathrm{f}=$ "formalin-killed cells"

$\mathrm{h}=$ "heat-killed cells"

${ }^{\mathrm{T}}$ Espécime tipo

A migração do complexo antígeno-anticorpo, evidenciada pela precipitação de uma ou mais bandas, permitiu observar durante os experimentos de imunodifusão, que o anti-soro ANTI-LQUSP03 não contém anticorpos para os antígenos LQUSP15, LQUSP22, nem para o antígeno ATCC7966. Na Figura 2a, observa-se que a reação de identificação sorológica ocorreu somente com o antígeno LQUSP03 extraído a $60^{\circ} \mathrm{C}$, evidenciado pela formação de uma única banda de precipitação.

Quando foi utilizado o anti-soro ANTI-LQUSP15 ocorreu relação cruzada completa, de difícil visualização, entre os antígenos LQUSP15 e LQUSP22 extraídos a $60^{\circ} \mathrm{C}$ e uma reação cruzada parcial entre os antígenos LQUSP15 e ATCC7966. O antisoro utilizado apresenta anticorpos para os antígenos LQUSP15, LQUSP22 e ATCC7966 (Figura 2b).

O uso do ANTI-LQUSP22, demonstrou haver identidade parcial entre os antígenos LQUSP22 e LQUSP15 e entre os antígenos LQUSP22 e ATCC7966. O anti- 
soro apresenta anticorpos para estes antígenos extraídos a $60^{\circ} \mathrm{C}$ (Figura 2c). Foi verificado ainda que o ANTI-ATCC7966 apresenta anticorpos para os antígenos extraídos a $60^{\circ} \mathrm{C}$, LQUSP03, LQUSP15 e LQUSP22, pela formação de reação cruzada parcial, não visualizada na foto, mas observada e mantida em desenhos, feitos para ajudarem na identificação das bandas (Figura 2d).

Para os antígenos extraídos a $100^{\circ} \mathrm{C}$, quando o anti-soro ANTI-LQUSP03 foi utilizado, não ocorreu relação de identidade entre LQUSP03, LQUSP15, LQUSP22 nem ATCC7966 (Figura 3a). Bandas se formaram próximo ao respectivo antígeno LQUSP03, evidenciando apenas que o ANTI-LQUSP03 contém anticorpos para este antígeno. O uso do anti-soro ANTI-LQUSP15 demonstrou que os antígenos LQUSP15 e LQUSP22 e os antígenos LQUSP15 e ATCC7966, quando aquecidos a $100^{\circ} \mathrm{C}$, apresentam uma relação cruzada completa e relação parcial, respectivamente (Figura 3b). O anti-soro contém anticorpos para o LQUSP03, mas não há relação de identidade antigênica.

Na figura 3c observa-se que o anti-soro ANTI-LQUSP22 contém anticorpos para todos os antígenos em teste, extraídos a $100^{\circ} \mathrm{C}$, pela formação de várias bandas de precipitação. Os antígenos LQUSP22 e LQUSP15, e os antígenos LQUSP22 e ATCC7966 apresentaram uma reação cruzada parcial. Na Figura 3d, os antígenos ATCC7966 e LQUSP15, assim como os antígenos ATCC7966 e LQUSP22 apresentam uma relação de identidade parcial. O anti-soro ANTI-ATCC7966 apresenta anticorpos para o antígeno LQUSP03, mas nenhuma relação de identidade. 
a)

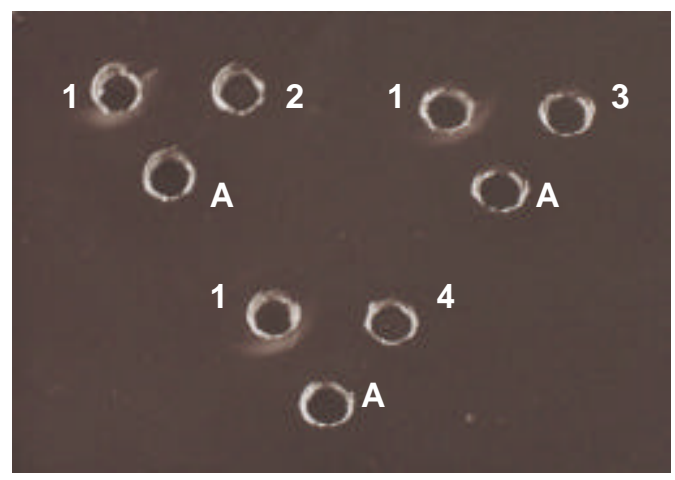

c)

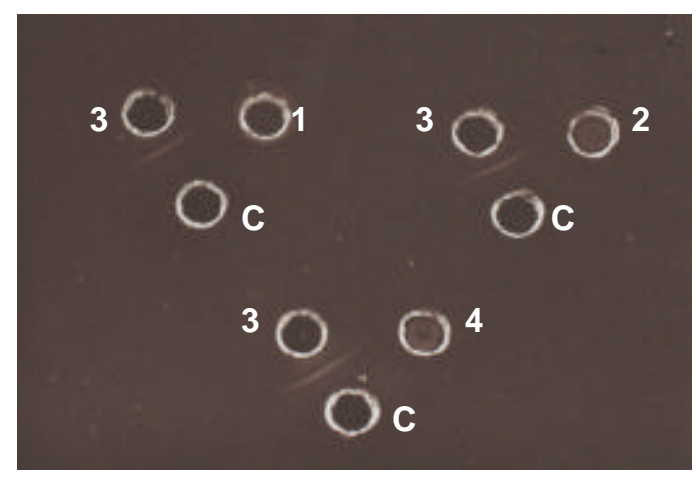

b)

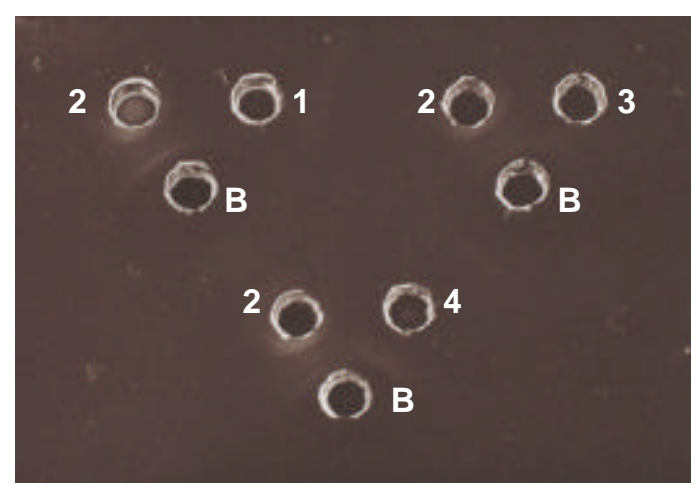

d)

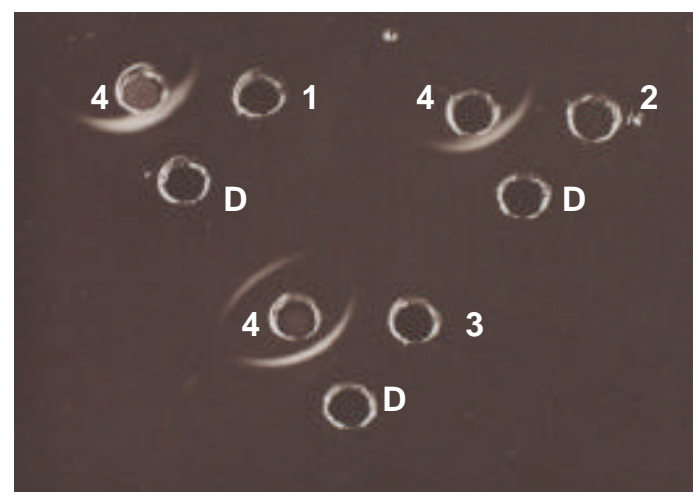

Figura 2 - Reação sorológica entre os anti-soros produzidos em coelhos e os antígenos bacterianos extraídos a $60^{\circ} \mathrm{C}$.
1 - antígeno LQUSP03
A - Anti-LQUSP03
2 - antígeno LQUSP15
B - Anti-LQUSP15
3 - antígeno LQUSP22
C - Anti-LQUSP22
4 - antígeno ATCC7966
D - Anti-ATCC7966 
a)

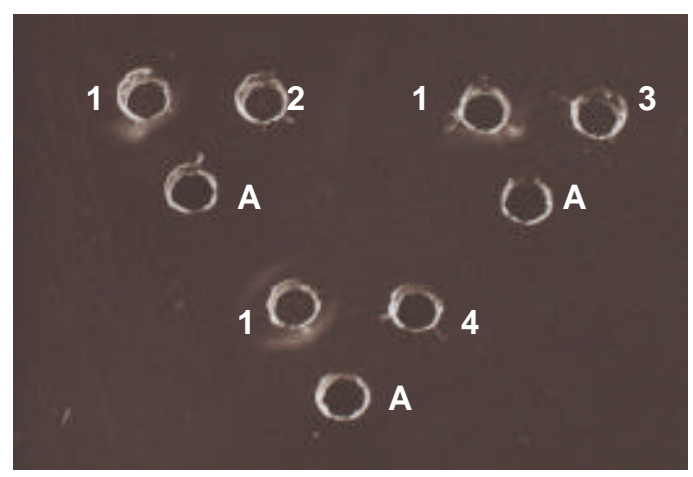

c)

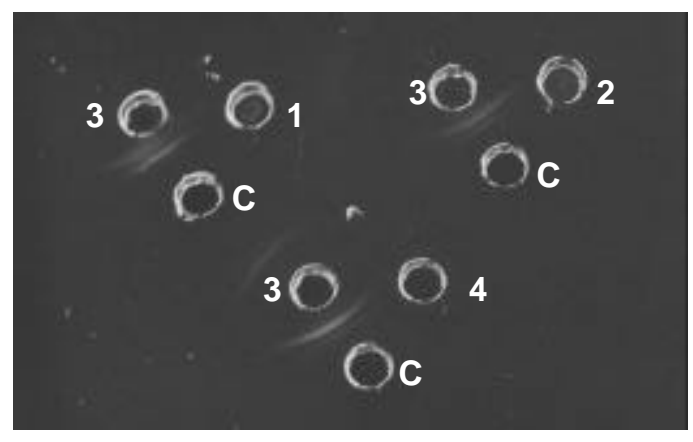

b)

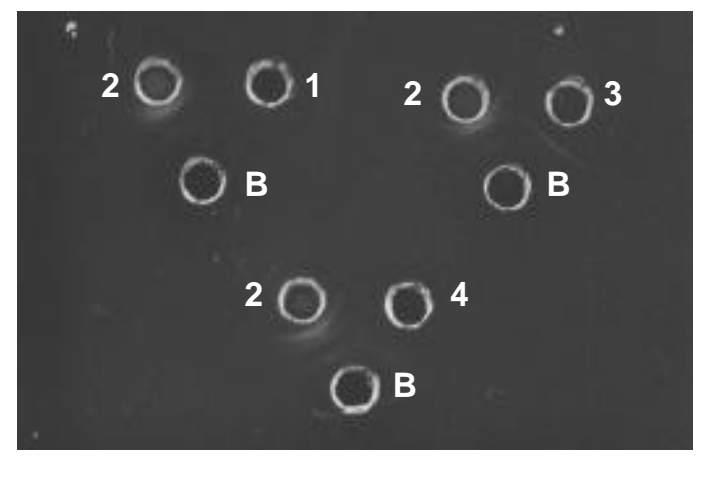

d)

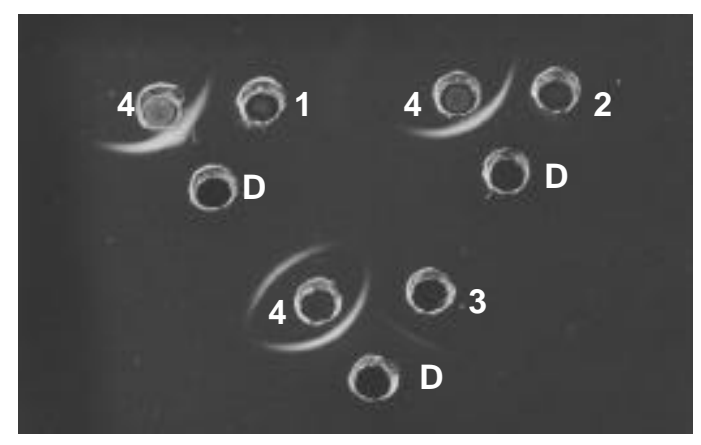

Figura 3 - Reação sorológica entre os anti-soros produzidos em coelhos e os antígenos bacterianos extraídos a $100^{\circ} \mathrm{C}$.
1 - antígeno LQUSP03
A - Anti-LQUSP03
2 - antígeno LQUSP15
B - Anti-LQUSP15
3 - antígeno LQUSP22
C - Anti-LQUSP22
4 - antígeno ATCC7966
D - Anti-ATCC7966 
Nos testes SDS-PAGE ("sódio dodecilsulfato - poliacrilamida gel eletroforese"), foi possível observar a divisão dos grupos de bactérias de acordo com a mobilidade relativa dos polipeptídeos, que mostraram a formação de diferentes bandas entre as linhagens estudadas e o meio de cultura utilizado para cultivo (Figura 4). Nenhuma das linhagens estudadas, independentemente do meio utilizado, apresentou igualdade entre si.

No meio de cultura YEA, a linhagem LQUSP03 apresentou três bandas com aproximadamente $90 \mathrm{kDa} ; 68,75 \mathrm{kDa}$ e $62,5 \mathrm{kDa}$, nenhuma destas bandas foi observada no espécime tipo. Entretanto, a linhagem LQUSP15 compartilha duas bandas com a linhagem LQUSP03, que são de $68,7 \mathrm{kDa}$ e $62,5 \mathrm{kDa}$. Uma banda de peso molecular equivalente a $33,61 \mathrm{kDa}$ é compartilhada entre os espécimes LQUSP15, LQUSP22 e ATCC7966. As bandas de peso $97,5 \mathrm{kDa} ; 86,25 \mathrm{kDa}$ e $31,94 \mathrm{kDa}$ são compartilhadas entre o espécime LQUSP15 e o espécime tipo de $A$. hydrophila.

A eletroforese realizada com células bacterianas cultivadas em meio suplementado com glucose, evidenciou a presença de uma mesma banda com aproximadamente $144,28 \mathrm{kDa}$ nas linhagens LQUSP15, LQUSP22 e no espécime tipo ATCC7966. As linhagens LQUSP15 e LQUSP22 compartilham uma banda com peso molecular de mais ou menos 128,57kDa e as linhagens LQUSP03 e LQUSP22 têm em comum uma banda com valor aproximado de 97,5kDa. 


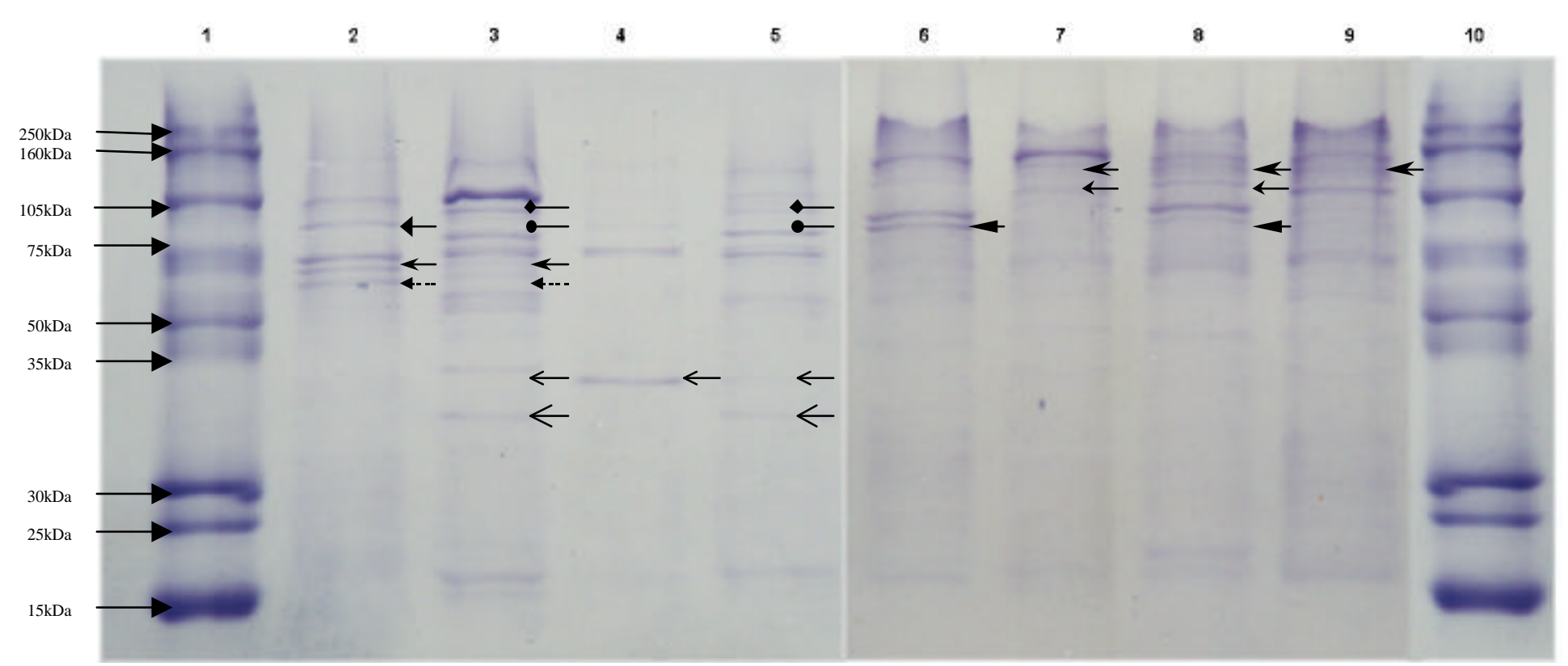

Figura 4 - SDS-PAGE das linhagens bacterianas cultivadas em dois meios de cultura diferentes. Bandas de 2 a 5 Meio YEA e de 6 a 9 Meio Glucose Agar. Bandas 1 e 10 - marcador de peso molecular indicado em kilodaltons; 2 e 6 LQUSP03; 3 e 7 - LQUSP15; 4 e 8 - LQUSP22; 5 e 9 - ATCC7966.

Meio YEA:

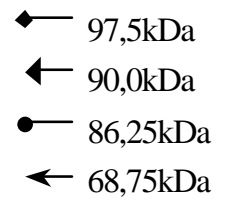

Meio Glucose Agar:

$$
\begin{aligned}
& \leftarrow-62,5 \mathrm{kDa} \\
& \leftarrow 33,61 \mathrm{kDa} \\
& \leftarrow 31,94 \mathrm{kDa}
\end{aligned}
$$

$<144,28 \mathrm{kDa}$

<... $128,57 \mathrm{kDa}$

- $97,5 \mathrm{kDa}$ 


\section{DISCUSSÃO}

As bactérias do complexo Aeromonas móveis, representadas pela espécie $A$. hydrophila, têm sido responsabilizadas por doenças em peixes como a hemorragia septicemica (Bullock et al., 1971; Egusa, 1978; Schäperclaus et al., 1992) e a doença ulcerativa dos peixes (Karunasagar et al., 1995). Sua ampla distribuição através do mundo deve-se, provavelmente, a sua grande capacidade de adaptação a diferentes ambientes aquáticos (Mateos et al., 1993) e, por isto, tem sido observada em diversas espécies de peixes de água doce e ocasionalmente em peixes marinhos, além de répteis, bovinos e no homem (Bullock at al., 1971, Khardori \& Fainstein, 1988). As doenças mais importantes causadas pelas Aeromonas móveis são observadas em sistemas de produção de peixes de água doce (Aoki, 1999).

Para o isolamento de bactérias do complexo Aeromonas, diversos meios seletivos têm sido desenvolvidos, porém a rotina de identificação das bactérias pertencentes à família Vibrionaceae pode ser baseada em alguns testes bioquímicos como: oxidase, teste de Hugh e Leifson O/F, arginina descarboxilase de Mdler ou de Thornley, lisina e ornitina de Mdler, motilidade, redução de nitrato, sensibilidade ao

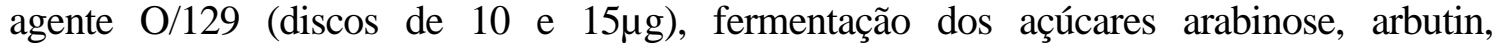
inositol, salicina e sucrose, teste de Voges-Proskauer (VP), tolerância ao sal (0, 3, 6, 8 e $10 \% \mathrm{NaCl}$ ) e produção de gás a partir da glucose (Lee \& Donovan, 1988).

De acordo com os testes bioquímicos realizados neste estudo, constatamos que a linhagem LQUSP03, isolada de surubim, anteriormente considerada Aeromonas hydrophila atípica, na verdade tratava-se de uma linhagem de Plesiomonas shigelloides, o que é evidenciado pelo fato deste organismo fermentar o açucar inositol, um traço muito raro nos gêneros Vibrio e Aeromonas, como já observado por Frerichs \& Millar, 
(1993). A Tabela 6 relaciona alguns testes para identificação entre as espécies de Aeromonas e Plesiomonas. Seus dados correspondem aos resultados obtidos por Popoff \& Veron (1976).

Tabela 6. Diferenciação entre as espécies de Aeromonas e Plesiomonas, modificado de Lee e Donovan (1988).

\begin{tabular}{ccccc}
\hline Testes & A. hydrophila & A. sobria & A. caviae & P. shigelloides \\
\hline TCBS & Y/- & - & Y/- & G/- \\
Gás a partir de glucose & $\mathrm{d}$ & + & - & - \\
Voges-Proskauer & + & + & - & - \\
Oxidação do gluconato & + & + & - & - \\
Lisina de Møler & + & + & - & + \\
Ornitina de Mdler & - & - & - & + \\
Ácido a partir de & & & & - \\
L-arabinose & + & - & + & - \\
Arbutin & + & - & + & + \\
Inositol & - & - & - & - \\
Salicina & + & $\mathrm{d}$ & + & - \\
Sucrose & + & + & + & - \\
Hidrólise de esculina & + & - & + & - \\
Quebra de elastina & + & - & - & + \\
Motilidade & + & + & + & + \\
Crescimento a $37^{\circ} \mathrm{C}$ & + & + & + & + \\
Crescimento a $42^{\circ} \mathrm{C}$ & - & + & - & - \\
Pigmento & - & - & - & + \\
\hline
\end{tabular}

$\mathrm{d}=$ característica difere de linhagem para linhagem.

Quando comparadas com a tabela resultante do trabalho feito por Aoki (1999), as características bioquímicas da linhagem LQUSP15 originada de tilápia, da linhagem LQUSP22 originada de pacu e do espécime tipo ATCC7966, comprovam que os isolados de peixes são bactérias A. hydrophila. As poucas diferenciações que ocorrem são aceitáveis, uma vez que a utilização das fontes de carboidrato rafinose e salicina 
podem diferir de uma linhagem para outra. Destaca-se, no entanto, a não hidrolisação de esculina pela linhagem de referência para A. hydrophila e pelo isolado LQUSP22 de pacu, o que não altera sua característica como bactéria pertencente ao complexo Aeromonas móveis (Tabela 7).

Tabela 7. Algumas caracteristicas bioquímicas das linhagens estudadas comparadas com características relatadas na literatura.

\begin{tabular}{|c|c|c|c|c|}
\hline Características & $\begin{array}{l}\text { A. hydrophila } \\
\text { Aoki (1999) }\end{array}$ & LQUSP15 & LQUSP22 & $\begin{array}{l}\text { A. hydrophila } \\
\text { ATCC7966 }^{\mathrm{T}}\end{array}$ \\
\hline Catalase & + & + & + & + \\
\hline Oxidase & + & + & + & + \\
\hline Urease & - & - & - & - \\
\hline Indol & + & + & + & + \\
\hline MR & $\mathrm{d}$ & - & - & - \\
\hline VP & + & + & + & + \\
\hline Hidrólise de Esculina & + & + & - & - \\
\hline DNAse & + & + & + & + \\
\hline Tween 20 & + & + & + & + \\
\hline Hemólise & + & + & + & + \\
\hline $\begin{array}{l}\text { Decarboxilaçãa de } \\
\text { Ornitina }\end{array}$ & - & - & - & - \\
\hline Ácido a partir de: & & & & \\
\hline Adonitol & - & - & - & - \\
\hline Amido & + & + & + & + \\
\hline Arabinose & d & + & - & + \\
\hline Dextrina & + & + & + & + \\
\hline Dulcitol & - & - & - & - \\
\hline Frutose & + & + & + & + \\
\hline Galactose & + & + & + & + \\
\hline Glicerina & + & + & + & + \\
\hline Glucose & + & + & + & + \\
\hline Inositol & - & - & - & - \\
\hline Lactose & d & - & - & - \\
\hline Maltose & + & + & + & + \\
\hline Manitol & + & + & + & + \\
\hline Manose & + & + & + & + \\
\hline Rafinose & d & - & - & + \\
\hline Salicina & d & + & + & - \\
\hline Sorbitol & d & - & - & - \\
\hline Sucrose & $\mathrm{d}$ & + & + & + \\
\hline Trealose & + & + & + & + \\
\hline Xilose & - & - & - & - \\
\hline
\end{tabular}

${ }^{\mathrm{T}}$ Espécime Tipo

$\mathrm{d}=$ característica difere de linhagem para linhagem. 
$\mathrm{O}$ uso de temperaturas entre $28-30^{\circ} \mathrm{C}$ é necessário porque muitas espécies de Aeromonas não crescem acima de $35^{\circ} \mathrm{C}$, ou quando isso ocorre, suas características bioquímicas não são típicas. (Hänninen et al. 1997). Os isolados de A. hydrophila diferem muito com relação a sua patogenicidade - algumas linhagens são altamente virulentas e outras não-virulentas. Wakabayashi et al., (1981), afirmam que isolados de Aeromonas móveis de diferentes origens variam amplamente, tanto com relação às suas propriedades bioquímicas, quanto em relação à virulência. Eddy ${ }^{1}$ e Kou ${ }^{2}$ citados por Aoki (1999) relatam que linhagens não virulentas ou fracamente patogênicas de $A$. hydrophila não são capazes de produzir gás e acetona a partir de glucose. As bactérias $A$. hydrophila (LQUSP15 e LQUSP22) isoladas de peixes e estudadas neste trabalho, produziram gás a partir de glucose e foram positivas para o teste de VP, o que evidencia sua virulência.

O uso de antibióticos e outros quimioterápicos como aditivos alimentares na criação de bovinos, suínos e aves e, mais recentemente, na produção de peixes e camarões, para o tratamento de infecções bacterianas e em doses sub-terapêuticas visando a prevenção de enfermidades, tem resultado em níveis cada vez maiores de resistência a antibióticos por bactérias patogênicas (Aoki et al., 1971; Vivekanandhan et al., 2002).

Em diversas partes do mundo, têm sido registradas linhagens de $A$. hydrophila com resistência múltipla a antibióticos ("multiple antibiotic resistence MAR”) (Pettibone et al., 1996; Son et al., 1997). No entanto, os efeitos destes químioterápicos sobre a ecologia bacteriana de peixes e do ambiente aquático utilizado para produção têm recebido pouca atenção, como já observado por DePaola et al. (1995).

\footnotetext{
${ }^{1}$ EDDY, B.P. Cephalotrichous, fermentative Gram-negative bacteria; the genus Aeromonas. Journal of Applied Bacteriology, v.23, p.216-249, 1960.

${ }^{2}$ KOU, G.H. Studies on the occurrence and biochemical properties of virulent and avirulent strains of freshwater fish pathogen, Aeromonas liquefaciens. Journal of the Fisheries Society of Taiwan, v.1, p.8-13, 1972.
} 
Segundo Adam et al. (1998) e Rhodes et al. (2000), a aqüicultura está tão relacionada a ocorrência de linhagens bacterianas resistentes, que pode haver uma relação interativa entre compartimentos distintos como hospitais e ambientes de aqüicultura. Afirmam, baseados na distribuição de plasmídeos resistentes à oxitetraciclina entre Aeromonas, que tais ambientes comportam-se de modo recíproco, havendo a necessidade de pesquisar-se o uso deste antibiótico na aqüicultura, a resistência asssociada a outras bactérias relevantes e ampliar a pesquisa de isolados para outras regiões geográficas e outros patógenos de peixes.

A linhagem LQUSP03 isolada de surubim e identificada como sendo Plesiomonas shigelloides, não só foi resistente a nove dos dezessete antibióticos testados via discos, dentre eles a tetraciclina, como também apresentou resistência à oxitetraciclina nas placas de agar, se considerarmos o valor de $30 \mu \mathrm{g} \cdot \mathrm{mL}^{-1}$ deste antibiótico como sendo o valor mínimo de referência, conforme sugerido por DePaola et al. (1988) para verificação da resistência a este antibiótico por linhagens de $A$. hydrophila. Foi observado que esta bactéria, isolada de surubim, é resistente aos antibióticos ampicilina e trimetoprim+sulfametoxazol, a exemplo de uma outra linhagem anteriormente isolada do bagre do canal (DePaola et al., 1995).

A exemplo do espécime tipo ATCC7966, as linhagens de A. hydrophila isoladas de tilápia e pacu foram uniformemente resistentes aos antibióticos ampicilina, amoxicilina, lincomicina, novobiocina, oxacilina, penicilina, rifampicina e trimetoprim+sulfametoxazol. O que causa preocupação é o fato da linhagem isolada de tilápia, LQUSP15, ter apresentado pouca sensibilidade aos antibióticos eritromicina, kanamicina e ao conjugado sulbactam+ampicilina, evidenciando tendência precoce de resistência a estes antibióticos.

O isolado de pacu, LQUSP22, além de resistente aos antibióticos citados anteriormente, já apresenta resistência a gentamicina, ao complexo sulbactam+ampicilia, à tetraciclina e à oxitetraciclina, mesmo quando presente em um meio cont endo este antibiótico a uma concentração de $100 \mu \mathrm{g} \mathrm{mL}^{-1}$. Esta observação permite inferir que a aplicação dos antibióticos mais comuns e de fácil acesso aos produtores de peixes, como a tetraciclina e a oxitetraciclina, em tratamentos de surtos bacterianos ou como 
preventivos, pode estar favorecendo o surgimento de cepas bacterianas resistentes também entre as espécies de peixes nativos brasileiros, produzidos comercialmente há pouco tempo, quando comparados com espécies introduzidas, como a tilápia ou o bagre do canal, produzidos comercialmente há muito mais tempo.

Vivekanandhan et al. (2002) observaram que isolados de A. hydrophila de peixes e camarões apresentavam resistência, dentre outros antibióticos, à novobiocina e à rifampicina e, de acordo com estud os realizados por DePaola et al. (1995), em viveiros de bagre do canal, os isolados de A.hydrophila foram resistentes em sua maioria à ampicilina e à tetraciclina e sensíveis a outras drogas. Segundo Lewis e Plumb (1985), mais de 38\% das Aeromonas isoladas de peixes doentes apresentam resistência à oxitetraciclina. Isto se deve provavelmente ao fator de transferência $\mathrm{R}$, que estas bactérias possuem (DePaola et al., 1988).

A eletroforese realizada em gel de poliacrilamida para proteínas bacterianas é uma técnica refinada que permite a identificação de linhagens de bactérias, freqüentemente até o nível individual. Isto é possível porque muitas linhagens bacterianas possuem ou perdem algumas bandas típicas. Em vários gêneros ou espécies heterogêneas, muitas linhagens têm seu próprio padrão de proteína individual típica. Porém, o emprego desta técnica não permite a diferenciação de espécies mutantes de bactérias devido às pequenas diferenças existentes entre a natureza e ao número de proteínas envolvidas. Os testes de SDS-PAGE realizados neste trabalho evidenciam que o isolado de surubim não pertence ao gênero Aeromonas, apresentando bandas de proteínas diversas das observadas no espécime tipo para A. hydrophila, corroborando os resultados bioquímicos.

Quando os perfis de proteínas totais dos isolados de A. hydrophila em tilápia e pacu são analisados, observa-se que ambos compartilham uma mesma banda de aproximadamente $33,61 \mathrm{kDa}$ com o espécime tipo, quando as linhagens foram cultivadas em YEA. Ao utilizarmos o meio enriquecido com glucose, que favorece $o$ desenvolvimento de cápsula (Garrote et al., 1992), a banda que é compartilhada por estas três linhagens passa a ser a que tem peso molecular aproximado de 144,28kDa. Mesmo assim, pode-se notar que os perfis protéicos entre as duas linhagens de $A$. 
hydrophila derivadas de peixes diferem entre si, não sendo totalmente idênticas e comprovando o que foi previamente observado nos testes bioquímicos e sorológicos foi isolada de diferentes espécies de peixes uma mesma espécie bacteriana, com padrão protéico e sorotipagem diversa.

A técnica de imunodifusão e outros métodos de análises imunológicas têm sido utilizados por muitos anos em estudos envolvendo o uso de soro produzido em peixes ou, mais frequientemente, em coelhos. Normalmente, as substâncias imunogênicas incluem antígenos individuais, como é o caso da gama-globulina humana, múltiplos antígenos presentes no soro total de animais, ou extratos bacterianos. A técnica de imunodifusão tem sido usada na identificação de antígenos de bactérias (ou outros organismos responsáveis por doenças) de peixes, em estudos de tipagem sorológica e classificação (Austin \& Austin, 1987).

Através da técnica de Ouchterlony pode-se detectar a presença de antígeno ou anticorpo, permitindo a comparação de vários antígenos e anti-soros (soros contendo anticorpos) sobre uma placa de ágar. $\mathrm{O}$ antígeno e o anticorpo difundem-se para formar um precipitado na zona de equivalência. Se as linhas de precipitados imunes formadas entre um anti-soro e dois antígenos diferentes fundirem-se, há similaridade (identidade) entre os dois antígenos. O cruzamento das linhas de precipitados, sem fusão, mostra a ausência de identidade. $\mathrm{O}$ número de linhas formadas entre um anti-soro e um antígeno indica o número mínimo de diferentes antígenos que estão sendo detectados pelo antisoro (Pelczar et al., 1996). Os anticorpos - substâncias estruturalmente semelhantes às glicoproteínas - sempre iniciam seus efeitos biológicos através de ligações com antígenos, que caracterizam-se por qualquer substância capaz de ser capturada por um anticorpo. Isso inclui qualquer tipo de molécula biológica como metabólitos, açúcares, lipídeos e hormônios, assim como macromoléculas do tipo carbohidratos complexos, fosfolipídeos, ácidos nucleicos e proteínas. Antígenos polivalentes contém epítopes de identificação múltiplos nos quais moléculas de anticorpos idênticos podem se ligar (Abbas et al., 1994).

Os resultados dos testes de aglutinação sorológica entre as céluals mortas por formalina e por calor, demonstram que as linhagens de A. hydrophila isoladas de tilápia 
e pacu (LQUSP15 e LQUSP22) apresentam antígenos estáveis ao calor ("heat-stable”) do tipo O, evidenciado pela manutenção dos dois grupos sorológicos observados durante a aglutinação por formalina, bem como durante a aglutinação com células mortas por calor. Este resultado é apoiado pelos resultados dos experimentos de imunopreciptação, onde a reação cruzada completa (identidade completa) entre os antígenos LQUSP15 e LQUSP22 a $60^{\circ} \mathrm{C}$ foi mantida mesmo após o seu aquecimento a $100^{\circ} \mathrm{C}$. Esta relação só ocorre quando se faz uso do anti-soro Anti-LQUSP15, preparado de uma linhagem de A.hydrophila isolada de tilápia.

Quando o anti-soro Anti-LQUSP22 foi usado, a relação entre os antígenos LQUSP15 e LQUSP22 passou a ser do tipo parcial, mas não impediu que houvesse identificação sorológica. Os demais anti-soros utilizados apresentaram relações parciais, não significativas, ou seja pouca ou nenhuma identidade.

O estudo sobre imunologia de peixes é um assunto ainda novo e o uso de vacinação contra enfermidades bacterianas e virais, apesar de recente, tem demonstrado bons resultados em relação aos aspectos científicos e econômicos, ao tornar mínima a utilização de químicos e antibióticos no ambiente de cultivo, principalmente devido às projeções que se faz sobre o crescimento da aqüicultura mundial e nacional, evidenciando que serão necessários programas de imunização contra enfermidades e produtos preventivos, ecologicamente seguros, para a manutenção da saúde de animais aquáticos. O presente trabalho identificou que o isolado de tilápia LQUSP15, devido sua maior variabilidade sorológica, é a melhor linhagem a ser estudada visando o desenvolvimento de produtos, como vacinas do tipo bacterinas, a serem utilizadas em diferentes espécies de peixes, no combate a enfermidades causadas por cepas de $A$. hydrophila, mesmo na presença de distintos sorotipos. Isto evidencia a importância de se investir na pesquisa de produtos imunológicos polivalentes e de amplo espectro que poderão ser utilizados em mais de uma espécie de peixe.

Diversos autores têm investigado o uso da vacinação como profilaxia contra infecções causadas por $A$. hydrophila, onde substâncias antigênicas (imunogênicas) são injetadas por via i.m. ou i.p., e observado aumento na titulação de anticorpos aglutinantes no soro dos peixes imunizados (Ruangpan et al., 1986; Stevenson, 1988; 
Karunasagar et al., 1991). No bagre de canal, vacinas por imersão utilizando-se antígenos polivalentes de A. hydrophila extraídos por ultra-som, geraram proteção, como relatado por Thune \& Plumb (1982). No entanto, segundo Aoki (1999), ainda é questionável a proteção fornecida a peixes quando as vacinas são aplicadas por via oral ou imersão. Apesar de apresentar vantagens e desvantagens, a vacinação caracteriza-se como um método seguro para o ambiente aquático e para a saúde humana, sendo considerado um dos mais importantes métodos para prevenção de doenças bacterianas em peixes (Zhou et al., 2002).

São ainda necessários estudos sobre os produtos extracelulares bacterianos produzidos por A. hydrophila: virulência, transferência de resistência por plasmídeos e sobre a capacidade de aderência e invasão das células dos hospedeiros por bactérias patogênicas cada vez mais resistentes a quimioterápicos, além de estudos sobre a eficácia das vacinas a serem desenvolvidas e a melhor maneira de administração de vacinas em peixes. 


\section{CONCLUSÕES}

1. O isolamento de surubim LQUSP03, caracterizou-se como Plesiomonas shigelloides.

2. Os isolados de tilápia LQUSP15 e pacu LQUSP22 caracterizaram-se como bactérias $A$. hydrophila, com capacidade virulenta.

3. Os isolados de peixe são resistentes a vários antibióticos comumente utilizados na piscicultura brasileira, o que pode influenciar sua eficácia devido o desenvolvimento de linhagens bacterianas resistentes.

4. Os testes SDS-PAGE indicaram que os isolados das três espécies de peixe e o representante de $A$. hydrophila possuem diferentes perfis de proteína. Os isolados de tilápia e pacu compartilham com o espécime tipo ATCC7966 uma banda protéica de aproximadamente 33,61kDa, em meio YEA. Em meio de cultura suplementado com glucose, a banda compartilhada por estas três linhagens passa a ter peso molecular aproximado de $144,28 \mathrm{kDa}$.

5. Foram isoaldas de diferentes espécies de peixes, tilápia LQUSP15 e pacu LQUSP22, a mesma espécie bacteriana com padrão protéico e sorotipagem diversa.

6. As linhagens de A. hydrophila isoladas de tilápia e pacu (LQUSP15 e LQUSP22) apresentam antígenos estáveis ao calor ("heat-stable") do tipo O.

7. O isolado de tilápia LQUSP15, em função de sua maior variabilidade sorológica, caracterizou-se como o antígeno com maior potencialidade 
para ser utilizado em estudos para o desenvolvimento de uma vacina do tipo bacterina. 


\section{REFERÊNCIAS BIBLIOGRÁFICAS}

ABBAS, A.K.; POBER, J.S.; LICHTMAN, A.H. Cellular and molecular immunology. Philadelphia: W.B. Saunders, 1994. cap.3, p.33-64: Antibodies and antigens.

ADAMS, C.A.; AUSTIN, B.; MEADEN, P.G.; McINTOSH, D. Molecular characterization of plasmid-mediated oxytetracycline resistance in Aeromonas salmonicida. Applied and Environmental Microbiology, v.64, p.4194-4201, 1998.

ALLAN, B.J.; STEVENSON, R.M.W. Extracellular virulence factors of Aeromonas hydrophila in fish infections. Canadian Journal of Microbiology, v.27, p.1114-22, 1981.

ANDERSON, D. P. Fish immunology. Neptune: T.F.H. Publ., 1974. 239 p.

ANSARY, A.; HANEEF, R.M.; TORRES, J.L.; YADAV, M. Plasmids and antibiotic resistance in A. hydrophila. Journal of Fish Biology, v.15, p.191-96, 1992.

AOKI, T. Drug-resistant plasmid from fish pathogens. Microbiological Sciences, v.5, p.219-223, 1988.

AOKI, T. Motile aeromonads (Aeromonas hydrophila). In: WOO, P.T.K.; BRUNO, D.W. (Ed.) Fish diseases and disorders. Oxon: CABI Publ., 1999. v.3: Viral, bacterial and fungal infections, cap.11, p.427-453.

AOKI, T.; EGUSA, S. Drug sensitivity of Aeromonas liquefaciens isolated from freshwater fishes. Bulletim of the Japanese Society for Scientific Fisheries, v.37, p.176-185, 1971. 
AOKI, T.; EGUSA, S.; OGATA, Y.; WATANABE, T. Detection of resistance factors in fish pathogen Aeromonas liquefaciens. Journal of General Microbiology, v.65, p.343-349, 1971.

AUSTIN, B.; AUSTIN, D.A. Bacterial fish pathogens: disease in farmed and wild fish. Chichester: Ellis Horwood, 1987. p.11-195.

AZAD, I.S.; SHANKAR, K.M.; MOHAN, C.V.; KALITA, B. Biofilm vaccine of Aeromonas hydrophila - standardization of dose and duration for oral vaccination of carps. Fish and Shellfish Immunology, v.9, p.519-528, 1999.

BULlOCK, G.L.; CONROY, D.A.; SNIESKO, S.F. Septicemic diseases caused by motile aeromonads and pseudomonads. In: SNIESKO, S.F.; AXELROD, H.R. (Ed.) Disease of fishes. Neptune:T.F.H. Publ., 1971. Book 2A: Bacterial diseases of fishes, p.21-41.

CAHILL, M.M. Virulence factors in motile Aeromonas - A review. Journal of Applied Bacteriology, v.69,p.1-16, 1990.

CARVALHAL, M. L.; ALTERTHUM, F. Morfologia e estrutura da célula bacteriana. In: TRABULSI, L.R.; ALTERTHUM, F.; GOMPERTZ, O.F.; CANDEIAS, J.A.N. Microbiologia. 3.ed. São Paulo: Atheneu, 1999. cap. 2, p. 9-23.

CHABOT, J.D.; THUNE, R.L. Proteases of the Aeromonas hydrophila complex. Journal of Fish Diseases, v.14, p.171-84, 1991.

CHANG, B.J.; BOLTON, S.M. Adherence haemagglutination and cell surface characteristics of motile aeromonads virulent for fish. Journal of Fish Disease, v.13, p.255-268, 1987.

CHRISTENSEN, W.B. Urea decomposition as means of differentiating Proteus and Paracolon cultures from each other and from Salmonella and Shigella types. Journal of Bacteriology, v.52, p.461-466, 1946. 
COSTA, A.B. Ictiopatologia e manejo sanitário em piscicultura intensiva. In: SIMPÓSIO SOBRE MANEJO E NUTRIÇÃO DE PEIXES, 2., Campinas, 1998. Anais. Campinas: CBNA. 1998a. p.73-96.

COSTA, A.B.; KANAI, K; YOSHIKOSHI, K. Serological characterization of atypical strains of Edwardsiella tarda isolated from SeaBream. Fish Pathology, v.33, n.4, p.265-274, 1998b.

DE FIGUEIREDO, J.; PLUMB, J.A. Virullence of different isolates of Aeromonas hydrophila in channel catfish. Aquaculture, v.11, p.349-354, 1971.

DEAN, H.M.; R.M. TOST. Fatal infection with Aeromonas hydrophila in a patient with acute myalogenous leukaemia. Annals Internal Medicine, v.66, p.1177-1179, 1967.

DEL CORRAL, F., SHOTTS, E.B.; BROWN, J. Adherence haemagglutination and cell surface characteristics of motile aeromonads virulent for fish. Journal of Fish Diseases, v.13, p.255-268, 1990.

DePAOLA, A.; PEELER, J.T.; RODRICK, G.E. Effect of oxytetracycline-medicated feed on antibiotic resistance of Gram-negative bacteria in catfish ponds. Applied and Environmental Microbiology, v.61, n.6, p.2335-2340, 1995.

DePAOlA, A.; FlYNN, P.A.; McPHEARSON, R.M.; LEVY, S.B. Phenotypic and genotypic characterization of tetracycline- and oxytetracycline-resistant Aeromonas hydrophila form cultured channel catfish (Ictalurus punctatus) and their environments. Applied and Environmental Microbiology, v.54, n.7, p.1861-1863, 1988.

EDDY, B.P. The Voges-Proskauer reaction and its significance: a review. Journal of Applied Bacteriology, v.24, p.27-41, 1961.

EGUSA, S. Infectious diseases of fish. Tokyo:Kouseisha Kouseikaku. 1978. 554p.

ENDO, T.; OGISHIMA, K.; HAYASAKA, H.; KANEKO, S.; OHSHIMA, S. Application of oxolinic acid as a chemotherapeutic agent against infections diseases in fishes - I. Antibacterial activity, chemotherapeutic effects and pharmacokinetics of 
oxolinic acid fishes. Bulletim of the Japanese Society for Scientific Fisheries, v.39, p.165-171, 1973.

EWING, W.H., DAVIN, B.R.; EDWARDS, P.R. The decarboxylase reactions of Enterobacteriaceae and their value in taxonomy. Public Health Laboratory, v.18, p.77-83, 1960.

EWING, W.H.; HUGH, R.; JOHNSON, J.G. Studies on the Aeromonas group. Bethesda: United States Department of Health, Education and Welfare, Communicable Disease Centre, 1961. 37p.

FIJAN, N.N.; KUNST, L.; TOMASEC, I. O liceju zarazne boden boden bolesti sarana nekim antibioticima i furozolidonom. Veterinary Archives, v.37, p.34-45, 1976.

FRAIRE, A.E. Aeromonas hydrophila infection. Journal of American Medical Association, v.239, p.192, 1978.

FRERICHS, G.N.; MILLAR, S.D. Manual for the isolation and identification of fish bacterial pathogens. Stirling: Pisces Press, 1993. 60 p.

FUKUI, H.; FUJUHARA, Y.; KANO, T. In vitro and in vivo antibacterial activities of florfenicol, a new fluorinated analog of thiamphenicol, against fish pathogens. Fish Pathology, v.22, p.201-207, 1987.

GARROTE, A.; BONET, R.; MERINO, S.; SIMON-PUJOL, M.D.; CONGREGADO, F. Occurence of a capsule in Aeromonas salmonicida. FEMS Microbiological Letters, v. 95, p.127-132, 1992.

GERHARDT, P.; MURRAY, R.G.E; WOOD, W.A.; KRIEG, N.R. (Ed.). Methods for general and molecular bacteriology. Washington: American Society of Microbiology, 1994. 791p.

GIBBS, E.L. Microbiology of water. Journal of Water Pollution, v.45, p.1244-1259, 1963. 
GRIFFIN, P.J.; SNIEZSKO, S.F.; FRIDDLE, S.B. A more comprehensive description of Bacterium salmonicida. Transactions of the American Fisheries Society, v.82, p.129-138, 1953.

HÄNNINEN, M.; OIVANEN, P.; HIRVELÄ-KOSKI, V. Aeromonas species in fish, fish-eggs, shrimp and freshwater. International Journal of Food Microbiology, v.34, p.17-26, 1997.

HÄSTEIN, Surveillance and control of marine fish disease. In: Office International des Épizooties. Rapports de synthèse sur les thème techniques présentès au Comité international ou aux Commissions tégionales. Paris, 1997. p.267-281.

HOLLIMAN, A. The veterinary approach to trout. In: BROWN, L. (Ed.). Aquaculture for veterinarians: fish husbandry and medicine. Oxford: Pergamon Press, 1993. cap.14, p.223-247.

HOSHINA, T. Studies on red-fin disease of eel. Special Research Report of Tokyo University of Fisheries, n.6, Tokyo, 1962. 105 p.

HOWARD, S.P.; BUCKLEY, J.T. Activation of the hole-forming toxin-related factor in cultures of Aeromonas species by enzyme-linked immunosorbent assay. Infection and Immunity, v.50, p.322-323, 1985.

HSU, T.C.; WALTMAN, W.D.; SHOTTS, E.B. Correlation of extracellular enzyme activity and biochemical characteristics with regard to virulence of Aeromonas hydrophila. Developmental of Biological Standardization, v.49, p.101-111, 1981.

JOHNSON, K.A.; AMEND, D.F. Efficacy of Vibrio anguillarum and Yersinia ruckeri bacterin applied by oral and anal intubation of salmonids. Journal of Fish Diseases, v.6, p.473-476, 1983.

JOSEPH, S.W.; DAILY, O.P.; HUNTER, W.S.; SEIDLER, R.J.; ALLEN, D.A.; COLWELL, R.R. Aeromonas primary wound infection of a diver in polluted waters. Journal of Clinical Microbiology, v.10, p.46-49, 1979. 
KANAI, K.; WAKABAYASHI, H. Purification and some properties of protease from Aeromonas hydrophila. Bulletim of the Japanese Society for Scientific Fisheries, v.50, 1360-1374,1984.

KARUNASAGAR, I.; SUGUMAR, G..; KARUNASAGAR, I. Virulence characters of Aeromonas sp. isolated from EUS-affected fish. In: SHARIF, M.; ARTHUR J.R.; SUBASINGHE, R.P. (Ed.). Diseases in Asian aquaculture II. Manila:Asian Fisheries Society. Fish Health Section, 1995. p.307-314.

KATAE, H.; KOUNO, K.; TAKASE, Y.; MIYASAKE, H.; HASHIMOTO, M.; SHIMIZU, M. The evaluation of piromidic acid as antibiotic in fish: as in vivo and in vivo study. Journal of Fish Diseases, v.2, p.321-335, 1979.

KETOVER, B.P.; YOUNG, L.S.; ARMSTRONG, D. Septicaemia due to Aeromonas hydrophila: clinical and immunological aspects. Journal Infectious Diseases, v.127, p.284-290, 1973.

KHARDORI, N.; FAINSTEIN, V. Aeromonas and Plesiomonas as etiological agents. Annual Review of Microbiology, 42, p.395-419, 1988.

KLUYVER, A.J.; VAN NIEL. C.B. Prospects for a natural system of classification for bacteria. Zentralblatt für Bakteriologie, Parasitenkunde Infektionskrannkheiten und Hygiene, v.94, p.369-403, 1936.

KUSUDA, R.; KAWAI, K. Bacterial diseases of cultured marine fish in Japan. Fish Pathology. v.3,n.4, p.221-227,1998.

LAEMMLI, U.K. Cleavage of structural proteins during the assembly of the head of bacteriophage $\mathrm{T}_{4}$. Nature, v.227, p.680-685, 1970.

LEE, J.V.; DONOVAN, T.J. Vibrio, Aeromonas and Plesiomonas. In: COLLINS, C.H.; GRANGE, J.M. (Ed.). Isolation and identification of microorganisms of medical and veterinary importance. London: The Society of Apllied Bacteriology; Academic Press. 1988. p.13-33. (Technical Series 21). 
LEVINE, M.; CARPENTER, D.C. Gelatin liquefaction by bacteria. Journal of Bacteriology, v.8, p.297-306, 1923.

LEWIS, D.H.; PLUMB, J.A. Bacterial diseases. In: PLUMB, J.A. (Ed.). Principal diseases of farm raised catfish Alabama: Auburn University, Alabama Agricultural Experiment Station, 1985. p.13-17. (Southern Cooperative Series Bulletin, 225).

MATEOS, D.; ANGUITA, J.; NAHARRO, G.; PANIAGUA, C. Influence of growth temperature on the production of extracellular virulence factors and pathogenicity of environmental and human strains of Aeromonas hydrophila. Applied Bacteriology, v.74, p.111-118, 1993.

MEAD, A.R. Aeromonas hydrophila in the leukoderma syndrome of Achatina fulica. Malacologia, v.9, p.43, 1969.

MEYER, F.P. Field treatments of Aeromonas liquefaciens infections in golden shiners. Progressive Fish-Culturist, v.26, p33-35, 1964.

MITCHELL, A.J.; PLUMB, J.E. Toxity and efficacy of Furanace on channel catfish infected experimentally with Aeromonas hydrophila. Journal of Fish Diseases, v.3, p. $93-100,1980$.

MIYAZAKI, T.; JO, Y. A histopathological study of motile Aeromonad disease in ayu. Fish Pathology, v.20, p.55-59, 1985.

MIYAZAKI, T.; KAIGE, N. Comparative histopatology of Edwardsiellosis in fishes. Fish Pathology, v.20, p.219-227, 1985.

NEWMAN, S.G. Aeromonas hydrophila a review. In: ANDERSON, D.P.; DORSON, M.; DOUBOURET, P. (Ed.). Les antigenes des micro organisms des poissons. Paris: Symposium International de Tallories Collection, Foundation of Marcel Merieux, 1982. p.87-117.

NIETO, T.P.; ELLIS, A.E. Characterization of extracellular matallo- and serineproteases of Aeromonas hydrophila strain $\mathrm{B}_{51}$. Journal of General Microbiology, v.132, p.1975-1979, 1986. 
NORD, C.E.; SJOBERG, L.; WADSTROM, T.; WRETLIND, B. Characterization of three Aeromonas and nine Pseudomonas species by extracellular enzymes and haemolysis. Medical Microbiology and Immunology, v.161, p.79-87, 1975.

OKAMOTO, A. Restrictions on the use of drugs in aquaculture in Japan. In: Office International des Epizooties. Chemotherapy in aquaculture: from theory to reality. Paris, 1992. p.109-114.

OLIVIER, G.; LALLIER, R.; LARIVIERE, S.. A toxigenic profile of Aeromonas hydrophila and Aeromonas sobria isolated from fish. Canadian Journal of Microbiology, v.27, p.330-333, 1981.

ØRSKOV, I.; ØRSKOV, F. The K antigens of Escherichia coli. Re-examination and reevaluatino of the nature of L-antigens. Acta Pathologica of Microbiology Scandinavian. Section B, v.78, p.593-604, 1970.

OUCHTERLONY, O. Handbook of immunodiffusion and immunoelectrophoresis. Michigan: Ann Arbor Science Publishers, Ann Arbor. 1968. p.215.

PAGE, L.A. Acetylmetylcarbinol production and the classification of aeromonas associated with ulcerative diseases of ectothermic vertebrates. Journal of Bacteriology, v.34, p.772-777, 1962.

PELCZAR Jr., J.M.; CHAN, E.C.S.; KRIEG, N.R. Microbiologia: conceitos e aplicações. 2.ed. São Paulo: MAKRON Books, 1997. v.2, p.517.

PETTIBONE, G.W.; MEAR, J.P.; SAMPSELL, B.M. Incidence of antibiotic and metal resistance and plasmid carriage in Aeromonas isolated from brown nullhead (Ictalurus nebulosus). Letters in Applied Microbiology, v.23, p.234-240, 1996.

PLUMB, J.A.; BOWSER, P.R. Microbial fish disease laboratory manual. Alabama: Auburn University, Alabama Agricultura Experiment Station, 1983. 95 p.

POPOFF, M.; VERON, M. A taxonomic study of the Aeromonas hydrophila Aeromonas punctata group. Journal of General Microbiology, v.94, p.11-22, 1976. 
POPOFF, M.Y.; COYNAULT, C.; KIREDJIAN, M.; LEMELIN, M. Polynucleotide sequence relatedness among motile Aeromonas species. Current Microbiology, v.5, p.109-114, 1981.

QUADRI, S.M.H.; GORDON, J.P.; WENDE, R.D.; WILLIAMS, R.P. 1976. Meningitis due to Aeromonas hydrophila. Journal of Clinical Microbiology, v.3, p.102-104, 1976.

RHODES, G.; HUYS, G.; SWINGS, J.; McGANN, P.;HINEY, M.; SMIYH, P.; PICKUP, R.W. Distribution of oxytetracycline resistance plasmids between Aeromonads in hospital and aquaculture environments: Implication of $\operatorname{Tn} 1721$ in dissemination of the tetracycline resistance determinant Tet A. Applied and Environmental Microbiology, v.66, p.3883-3890, 2000.

ROBERSON, B. S. Bacterial agglutination. In: STOLEN, J. S.; FLETCHER, T. C.; ANDERSON, D. P.; ROBERSON, B.S.; VAN NUISWINKEL, W. B. (Ed.). Techniques in fish immunology. Fair Haven: SOS Publications, 1990. v.1, p.81-86.

ROBERTS, R.J. Fish pathology. London: Bailliere Tindall, 1978. 318 p.

ROBERTS, R.J. Motile Aeromonad Septicaemia. In: INGLIS, V.; ROBERTS, R.J.; BROMAGE, N.R. (Ed.). Bacterial diseases of fish Oxford: Blackwell Science, 1993. cap.8, p.143-55.

ROMBOUT, J.W.H.M.; LAMERS， C.H.J.;HELFRICH， M.H.; DEKKER， A.; TAVERNE-THIELE, A.J. Uptake and transport of intact macromolecules in the intestinal epithelium of carp (Cyprinus carpio L.) and the possible immunological implications. Cell and Tissue Research, v.239, p.519-530, 1985.

RUANGPAN, L.; KITAO, T.; YOSHIDA, T. Protective efficacy of Aeromonas hydrophila vaccines in Nile tilapia. Veterinary Immunology and Immunopathology, v.12, 345-350, 1986.

SAKAI, D.K. Loss of virulence in a protease-deficience mutant of Aeromonas salmonicida. Infection and Immunity, v.48, p.146-152, 1985a. 
SAKAI, D.K. Significance of extracellular protease fro growth of a heterotrophic bacterium Aeromonas salmonicida. Applied and Environmental Microbiology, v.50, p.1031-1037, 1985 b.

SALTON, R.; SCHNICK, S. Aeromonas hydrophila peritonitis. Cancer Chemotherapy Reports, v.57, p.489-491, 1973.

SANTOS, Y.; PAZOS, F.; TORANZO, A.E. Biochemical and serological analysis of Vibrio anguillarum related organisms. Diseases of Aquatic Organisms, v.26, p.6773, 1996.

SCHÄPERCLAUS, W.; KULOW, H.; SCHRECKEBACH, K. Infectious abdominal dropsy. In: SCHÄPERCLAUS, W. (Ed.). Fish diseases. Berlin: AkademieVerlag, 1992. v. 1, p.401-458.

SCHUBERT, R.H.W. The taxonomic and nomenclature of the genus Aeromonas Kuyver and van Niel 1936. I. Suggestions on the taxonomy and nomenclature of the aerogenic Aeromonas spp. International Journal of Systematic Bacteriology, v.17, p.23-27, 1967.

SCHUBERT, R.H.W. Infrasubspecific taxonomy of Aeromonas hydrophila (Chester 1901) Stanier 1943. Zentralblatt fur Bakteriologie Parasitenkunde Infektionskranheiten und Hygiene, v.211, p.406-408, 1969.

SCHUBERT, R.H.W. Genus II. Aeromonas. In: BUCHANAN, R.E.; GIBBONS, N.E. (Ed.). Bergey's manual of determinative bacteriology. 8.ed. Baltimore:William e Wilkins, 1974. p.345-348.

SEAMAN, W.R. Notes on a bacterial disease of rainbow trout in a Colorado hatchery. Progressive Fish-Culturist, v.13, p.139-141, 1951.

SHAW, D.H.; HODDER, A.J. Lipopolysaccharides of the motile aeromonads; core oligosaccharide analyses as na aid to taxonomic classification. Canadian Journal of Microbiology, v.24, p.864-868, 1978. 
SHOTTS, E.B.; TSU, T.C.; WALTMAN, W.D. Extracellular proteolytic activity of Aeromonas hydrophila complex. Fish Pathology, v.20, p.37-40, 1985.

SHOTTS, E.B.; GAINES, J.L.; MARTIN, L.; PRESTWOOD, A.K. Aeromonas induced deaths among fish in a eutrophic inland lake. Journal of American Medical Association, v.162, p.603-607, 1972.

SIMMONS, J.S. A culture medium for differentiating organisms of typhoid-colon aerogenes groups and for isolating of certain fungi. Journal of Infectious Diseases, v.39, p.209-241, 1926.

SNIEZSKO, S.F. Genus IV. Aeromonas Kluyver e van Niel 1936. In: BREED, R.S.; MURRAY, E.D.G.; SMITH, R. (Ed.). Bergey's manual of determinative bacteriology. 7.ed. Baltimore:Williams \& Wilkins. 1957. p.189-93.

SON, R.; RUSUL, G.; SAHILAH, A.M.; ZAINURI, A.; RAHA, A.R.; SALMAH, I. Antibiotic resistance and plasmid profile of Aeromonas hydrophila isolates from cultured fish, Telapia (Telapia mossambica). Letters in Applied Microbiology, v.24, 479-482, 1997.

SØRENSEN, U.B.S.; LARSEN, J.L. Serotyping of Vibrio anguillarum. Applied and Environmental Microbiology, v.51,p.593-597, 1986.

STEVENSON, R.M.W. Vaccination against Aeromonas hydrophila. In: ELLIS, A.E. (Ed.). Fish vaccine. London: Academic Press, 1988. p.112-123.

STUKUS, P.E. Investigating microbiology: a laboratory manual for general microbiology. Orlando: Harcourt Brace \& Company, 1997. 509p.

TAKAHASHI, Y.; KUSUDA, R. Studies on the scale protrusion diseases of carps. Fish Pathology, v.12, p.15-19, 1977.

THUNE, R.L.; PLUMB, J.A. Effect of delivered method and antigen preparation on the production of antibodies against Aeromonas hydrophila in channel catfish. Progressive Fish Culturist, v.44, p.53-54, 1982. 
THUNE, R.L.; GRAHAM, T.E.; RIDDLE, L.M.; AMBORSKI, R.L. Effects of Aeromonas hydrophila extracellular products and endotoxins. Transactions of the American Fisheries Society, v.111, n.6, p.749-754, 1982a.

THUNE, R.L; GRAHAM, T.E.; RIDDLE, L.M.; AMBORSKI, R.L. Extracellular products and endotoxin form Aeromonas hydrophila: Effects on age-0 channel catfish. Transactions of the American Fisheries Society, v.111, n.3, p.404-408, 1982b.

THUNE, R.L.; JOHNSON, M.C.; GRAHAM, T.E.; AMBORSKI, R.L. Aeromonas hydrophila $\beta$-haemolysin: Purification and examination of its role in virulence of $\mathrm{O}$ group channel catfish Ictalurus punctatus Rafinesque. Journal of Fish Diseases, v.9, p.5-62, 1986.

TORANZO, A.E., BAYA, A.M., ROBERSON, B.S., BARJA, J.L., GRIMES, D. J.; HETRICK, F.M. Specificity of slide agglutination test for detecting bacterial fish pathogens. Aquaculture, v.61, p.81-97, 1987.

TRABULSI, L.R.; ALTERTHUM, F.; GOMPERTZ, O.F.; CANDEIAS, J.A.N. Microbiologia. 3.ed. São Paulo: Atheneu, 1999. p.586.

VIVEKANANDHAN, G.; SAVITHAMANI, K.; HATHA, A.A.M.; LAKSHMANAPERUMALSAMY, P. Antibiotic resistance of Aeromonas hydrophila isolated from marketed fish and prawn of South India. International Journal of Food Microbiology, v.76, p.165-168, 2002.

WAKABAYASHI, H.; KANAI, K.; HSU, T.C.; EGUSA, S. Pathogenic activities of Aeromonas hydrophila biovar hydrophila (Chester) Popoff and Veron, 1976 to fishes. Fish Pathology, v.15, p.319-325, 1981.

ZHOU, Y-C.; HUANG, H.; WANG, J.; ZHANG, B.; SU, Y-Q. Vaccination of the grouper, Epinephalus awoara, against vibriosis using the ultrasonic technique. Aquaculture, v.203, p.229-238, 2002. 